\title{
Diabetes mellitus: a prothrombotic state Implications for outcomes after coronary revascularization
}

\author{
Clarissa Cola' \\ Salvatore Brugaletta' \\ Victoria Martín Yuste' \\ Bieito Campos' \\ Dominick J Angiolillo² \\ Manel Sabaté \\ 'Interventional Cardiology Unit, \\ Department of Cardiology, Sant Pau \\ University Hospital, Barcelona, Spain; \\ ${ }^{2}$ Interventional Cardiology Unit, \\ Shands Jacksonville, University \\ of Florida, Florida, USA
}

\begin{abstract}
Coronary stent thrombosis is a serious problem in the drug-eluting stent era. Despite aggressive antiplatelet therapy during and after percutaneous coronary intervention (PCI), the incidence of sub-acute stent thrombosis remains approximately $0.5 \%-2 \%$, which may represent a catastrophic clinical situation. Both procedural factors and discontinuation of antiplatelet therapy are normally associated with this event. We report on simultaneous stent thromboses of two drug-eluting stents implanted in two different vessels, which resulted in a life-threatening clinical condition. Possible contributing factors that led to synergistic thrombotic effects are discussed.
\end{abstract} Keywords: diabetes mellitus, platelet function, antiplatelet therapy, drug-eluting stent, stent thrombosis

\section{Simultaneous thromboses of two coronary artery stents: fostering bad synergies}

The patient is a 47-year-old woman from Morocco with a history of insulin-requiring type 2 diabetes mellitus (DM), dyslipidemia, and obesity (body mass index: 33), admitted to our institution during the acute phase of ST elevation myocardial infarction (STEMI). One week before the current admission, the patient had been admitted to another center with progressive angina pectoris (functional class III). Coronary angiography revealed severe coronary stenoses in the proximal segment of the right coronary artery (RCA) and in the distal segment of the left anterior descending (LAD) artery. At that time, PCI of both lesions was performed by implanting a $2.25 \times 8 \mathrm{~mm}$ sirolimus-eluting stent $\left(\right.$ Cypher $^{\circledR}$, Cordis, Johnson and Johnson) in the distal LAD and a $2.5 \times 13 \mathrm{~mm}$ stent in the proximal RCA. The patient was discharged on dual antiplatelet therapy (acetylsalycilic acid, ASA) $100 \mathrm{mg}$ per day and clopidogrel $75 \mathrm{mg}$ per day). Five days after the procedure, however, the patient decided to stop ASA although remained on clopidogrel. Two days later, the patient suffered from STEMI involving both anterior and inferior territories on the ECG. She also suffered repeated episodes of ventricular fibrillation, but was successfully defibrillated. The patient required inotropic support to maintain arterial pressure stability and was intubated because of repeated arrythmias. Emergency coronary angiography was performed and revealed thromboses of both stents (Figure 1). RCA thrombosis was tackled first with abciximab bolus + infusion. The passage of the guidewire through the stent was very difficult requiring the use of different wires. A hydrophilic wire was initially passed through the stent, but neither a thrombus aspiration catheter nor a $1.5 \times 10 \mathrm{~mm}$ angioplasty balloon could cross through the stent successfully. Not until a second wire was sited in parallel (Figure 2A), while the balloon remained inserted over the first wire at the point where it stopped, could we successfully dilate the stent with 

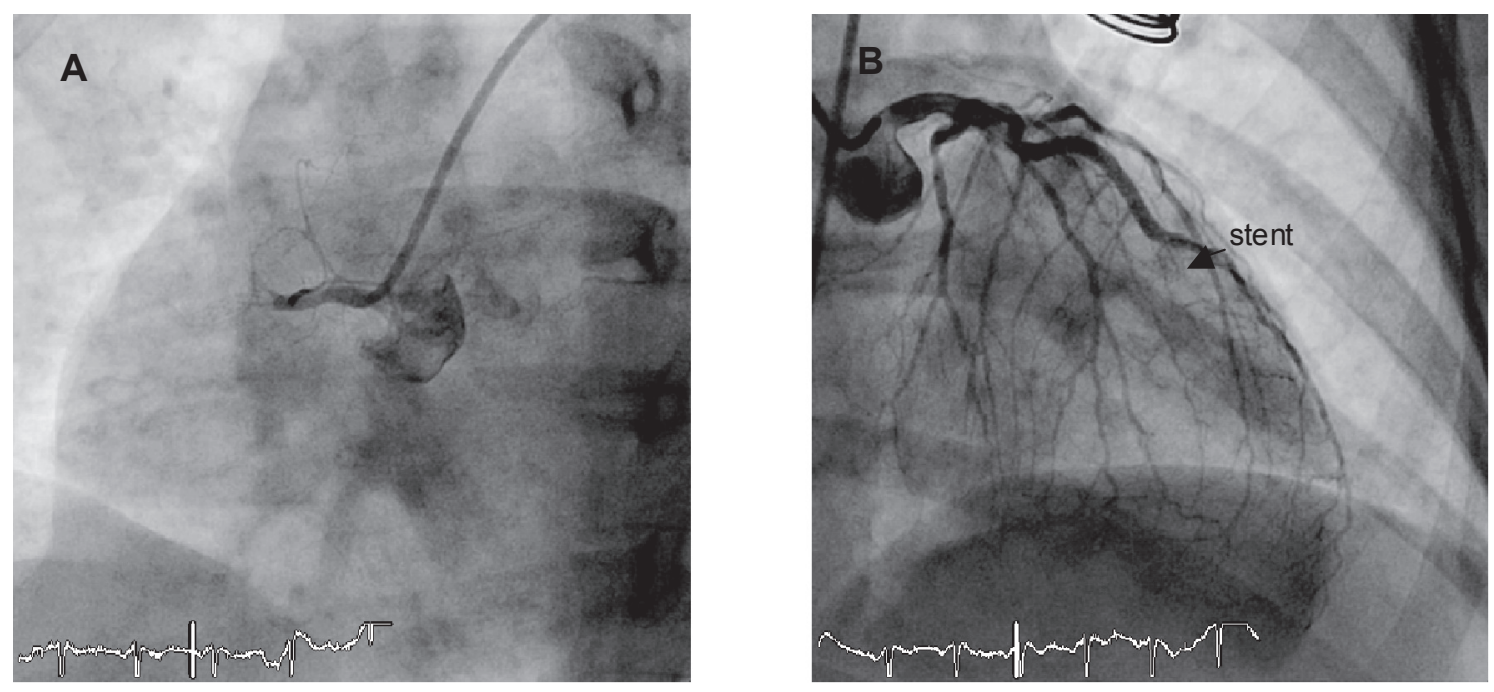

Figure I Angiographic images of stent thrombosis on RCA (A) and LAD (B).
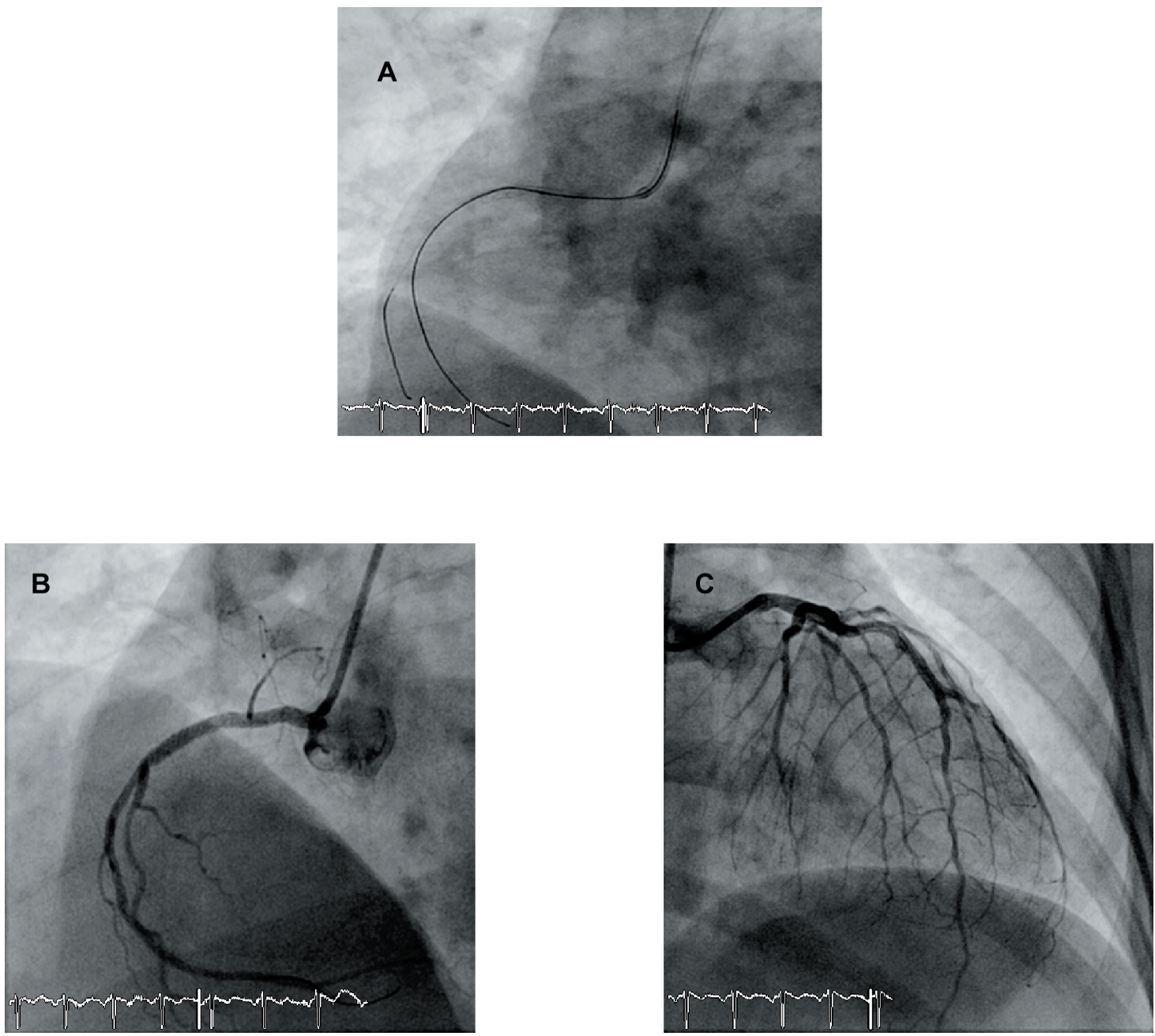

Figure 2 Panel A: successful passage of the wire, while the balloon is inserted over another wire at the place where it stopped. Panel $\mathbf{B}$ and $\mathbf{C}$ : Final angiographic result on RCA (B) and LAD (C). 
noncompliant balloons (2.5 and $3.0 \mathrm{~mm}$ in diameter). Finally a new drug-eluting stent (DES) (Xience ${ }^{\mathrm{TM}}$, Abbott Vascular $3.0 \times 28 \mathrm{~mm}$ ) was used to cover the entire segment including the more proximal segment of the RCA up to the distal part of the previously implanted stent. A DES was chosen because the patient was diabetic. A good angiographic result (TIMI 3 flow) was obtained (Figure 2B). The LAD artery was treated sequentially. In this vessel, thrombus aspiration was effective and the result was optimized using a noncompliant balloon dilatation $(2.5 \times 9 \mathrm{~mm})$ gaining a final TIMI 3 flow (Figures 2B-C). The patient could be transferred to her referral hospital and the initial outcome was uneventful. Five days later, she was discharged on dual antiplatelet high-dose regimen (ASA $300 \mathrm{mg}$ per day and clopidogrel $150 \mathrm{mg}$ per day). Before discharge, she received intensive counseling on the need for compliance with medication, and on secondary prevention to avoid further thrombotic events.

\section{Discussion}

Numerous reports describe the occurrence of acute ( $<24$ hours), subacute ( $<30$ days), late ( $>30$ days), and very late ( $>12$ months) stent thrombosis after DES implantation. ${ }^{1,2}$ However, the true incidence of stent thrombosis may be underestimated in clinical trials and could occur at substantially higher rates in the real world, where more complex lesions are treated. ${ }^{3,4}$ Several factors that contribute to stent thrombosis have been recognized, such as procedure-, patient-, and lesion-related factors, thrombogenity of the stent, impaired re-endothelization, and antiplatelet therapy (Table 1). In recent years, aggressive antiplatelet therapy during PCI, including use of ASA, thienopyridines, and glycoprotein IIb/IIIa inhibitors, has reduced the risk of post-procedural thrombotic complications. ${ }^{5}$ Nonetheless, the incidence of acute stent thrombosis remains approximately $0.5 \%-2 \%$.

In our case, the simultaneous thrombosis of both stents suggested a systemic disturbance, to which many factors might have contributed. Among the procedure-related factors, smaller final lumen dimensions, especially with stent malapposition and/or underexpansion appear to be important for the development of in-stent thrombosis. ${ }^{6}$ These procedural problems are more important with DES, in which the stent length, stent underexpansion, and residual stenosis have been associated with risk for stent thrombosis. ${ }^{7}$ These problems, which may be involved in both bare metal and DES thromboses, can be prevented during the intervention by means of judicious stent deployment and implantation. Good selection of the stent size, proper coverage of the entire lesion length, and the achievement of good expansion of the stent are mandatory during PCI. Technical difficulties encountered during recanalization of the current thrombosed stent in the RCA suggested both underexpansion and incomplete stent apposition which, with the small stent size $(2.5 \mathrm{~mm})$, may have been involved in the pathogenesis of the thrombosis. Furthermore, stent size in the LAD was also small $(2.25 \mathrm{~mm})$. It is worthwhile considering other potential concomitant factors such as resistance to antiplatelet therapy (clopidogrel and/or ASA), compliance to therapy (which plays a major role in this case), and the grade of inflammation. Antiplatelet resistance and inflammation are known determinants of accelerated atherosclerosis in diabetics. ${ }^{8}$

Certain stent designs and materials may predispose to thrombogenity. Thus the open-cell stent, compared with the

Table I Factors implicated in pathophysiology of in-stent thrombosis

Procedure-related factors

Stent malapposition and/or underexpansion

Stent length, multiple stent

Persistent coronary blood flow

Positive remodelling

Dissections

Residual stenosis

Late stent malapposition due to thrombus

Patient-related factors

Low-ejection fraction

Diabetes mellitus

Advanced age

Renal failure

Variability to wound healing

Antiplatelet therapy discontinuation

Lesion-related factors

Acute coronary syndromes

Bifurcations

In-stent restenosis lesions

Antiplatelet therapy

Discontinuation of antiplatelet therapy

Hyporesponsiveness

Stent factors

Design of stent (open-cell vs closed-cell)

Strut thickness

Polymer type

Drug of drug-eluting stents (lipophility)

Impaired re-endothelialization

Adapted from Luscher TF, Steffel J, Eberli FR, et al. Drug-eluting stent and coronary thrombosis: biological mechanisms and clinical implications. Circulation. 2007; |15:1051-1058. 
closed-cell, appeared to generate greater platelet activation during the 30 days after implantation in one study. ${ }^{9}$ Strut thickness, and polymer type and thickness, may also play an important role. Nonerodable polymers of the Cypher and Taxus provoke chronic eosinophilic infiltration of the arterial wall, suggestive of hypersensitivity reactions in a small number of cases. ${ }^{10}$ Furthermore, drugs eluted from DES may exert a prothrombotic effect. Rapamycin (sirolimus), for example, may increase both thrombin- and tumor necrosis factor- $\alpha$-induced endothelial tissue factor expression and activity. ${ }^{11}$ At the same time, paclitaxel enhances tissue factor expression and activity in endothelial cells. ${ }^{12}$ In addition, both drugs may easily penetrate into the artery wall owing to their lipophylic properties, with chronic retention of the drug in the surrounding artery tissue, which may also contribute to the prothrombotic environment after DES deployment. ${ }^{13}$ Another contributing factor may be the delayed or impaired endothelialization of DES. In vitro rapamycin and paclitaxel can inhibit proliferation and migration of vascular smooth muscle cells, and may also suppress endothelial cells. ${ }^{14}$

Other factors that may influence the healing are likely to be lesion-related, such as primary stenting in acute MI due to the presence of a pronounced inflammatory and thrombogenic environment of the exposed necrotic core to flowing blood, accompanied by enhanced platelet reactivity, ${ }^{3,15}$ and patient-related, such as antiplatelet therapy discontinuation, renal failure, DM, and a lower ejection fraction, which have all been reported in clinical studies. ${ }^{3}$ In particular, discontinuation of antiplatelet therapy has been observed to be strongly associated with DES thrombosis. ${ }^{1}$ The appropriate duration of the long-term antiplatelet regimen for prevention of DES thrombosis still needs to be assessed in randomized prospective trials. A further problem has emerged: hyporesponsiveness to antiplatelet therapy by some groups of patients, in particular diabetic patients. ${ }^{16}$ Patients with DM are characterized by a prothrombotic status, related to endothelial dysfunction, impaired fibrinolysis, increased coagulation factors, and increased platelet reactivity and turnover. ${ }^{17,18}$ Despite the clinical benefit achieved with antiplatelet agents, these patients continue to have an increased risk of ischemic events compared with nondiabetics. ${ }^{19}$ Diabetic patients also have reduced responsiveness to oral antiplatelet therapy, either ASA or clopidogrel, ${ }^{20-22}$ which is potentially related to the need for insulin therapy. ${ }^{23}$ In particular, the hyporesponsiveness to clopidogrel may be partially averted with a high dose of clopidogrel (150 mg/day). ${ }^{24,25}$

In conclusion, our patient presented several factors that fostered bad synergies. Her diabetes could have heightened platelet reactivity. In this milieu, the early suspension of ASA might act as a precipitating factor in a setting of potential under-expansion and small DES. The involvement of both coronary arteries supports the systemic activation of the thrombotic state. Good stent selection and proper implantation may prevent many stents from being thrombosed in prothrombotic environment.

\section{Limitations}

Unfortunately, the patient was on infusion of IIb/IIIa antagonists, so that platelet function could not be measured with optical aggregometry. Moreover, the discussion on the probable underexpansion or malapposition of the thrombosed stent based on the technical difficulties encountered during the coronary angioplasty can only be considered a hypothesis. To demonstrate this issue intravascular ultrasound should have been performed.

\section{Diabetes mellitus: a prothrombotic state. Implications for outcomes after coronary revascularization Introduction}

Diabetes mellitus (DM) affects 150 million people worldwide. In particular, type $2 \mathrm{DM}$ is endemic and the incidence is increasing. ${ }^{26}$ The leading cause of disability and premature mortality among diabetics is cardiovascular disease. ${ }^{27}$ DM increases the risk for coronary heart disease, stroke, and peripheral arterial disease from 2 -fold to 4 -fold. ${ }^{28,29}$ The increased risk is independent of and in addition to other cardiovascular risk factors. ${ }^{30}$ Importantly, the risk of myocardial infarction (MI) is 3- to 5-fold higher in type $2 \mathrm{DM}$. A diabetic subject with no history of MI has the same long-term risk as a non-DM subject with a past history of MI. Patients with DM usually show a diffuse and severe coronary artery disease. Coronary artery revascularization of diabetics continues to be a challenge: these patients suffer from a higher rate of repeated revascularization and worse outcomes after PCI, compared with non-DM patients. The increased atherothrombotic risk in DM patients is related to their pro-inflammatory and prothrombotic status. Platelets from diabetic subjects show increased adhesiveness and an exaggerated aggregation. Reduced responsiveness of diabetic patients to antiplatelet therapy has also been documented. The introduction of DES has improved outcomes in diabetic patients. Although DES are now widely used, only limited data are available for systematic evaluation of their safety in this specific population. Importantly, recent 
data have raised concerns about increased risks of stent thrombosis (ST) and mortality over longer periods of followup. This review focuses on the mechanisms leading to the prothrombotic status which characterizes DM patients, and its implications for coronary revascularization outcomes, including stent thrombosis, in particular antiplatelet therapy responsiveness and possible alternatives to improve clinical outcomes.

\section{Diabetes: a prothrombotic state}

$\mathrm{DM}$ is associated with an increased atherothrombotic risk. Patients with DM and coronary artery disease show a high rate of recurrence after MI. ${ }^{16}$ Atherothrombotic disease is accelerated in subjects with type 1 and type $2 \mathrm{DM}$, accompanied by diverse underlying mechanisms, despite the common trace of hyperglycemia. The main feature of type $2 \mathrm{DM}$ is insulin resistance, which precedes the development of hyperglycemia. ${ }^{31}$ In contrast, in type $1 \mathrm{DM}$, hyperglycemia is the dominant abnormality with insulin resistance appearing in longer standing patients who develop renal disease. ${ }^{32}$ Insulin resistance and hyperglycemia have several important effects. altering coagulation and platelet function, contributing to a prothrombotic status.

Insulin resistance determines increased levels of the fibrinolytic inhibitor, Plasminogen Activator Inhibitor-1 (PAI-1), the link between type 2 DM and fibrinolysis suppression. ${ }^{33}$ Furthermore, insulin resistance is associated with the increased expression and production of different coagulation factors promoting platelet adhesion to the vascular sub-endothelium. ${ }^{34}$

Insulin resistance affects the cellular phases of hemostasis, also impairing endothelial and platelet function, and endothelial-dependent vasodilatation. ${ }^{35-37}$. Platelet function is regulated by insulin ${ }^{38,39}$ which in normal conditions antagonizes the effect of a number of agonists, ${ }^{40}$ the adhesion or aggregation of platelets is upregulated in insulin-resistant subjects. ${ }^{17,41}$ Up-regulation of the $\mathrm{P} 2 \mathrm{Y}_{12}$ ADP receptor signaling pathway has been shown in type 2 DM platelets, thus contributing to increased platelet reactivity in these patients. $^{16}$
The effect of insulin resistance on the function of platelets is related to levels of intracytosolic calcium, a mediator of platelet activation. ${ }^{42}$ Insulin decreases the intracellular concentration of calcium in platelets of insulin-sensitive subjects in vivo and in vitro, and appears to increase the intra-platelet calcium concentrations in insulin-resistant subjects, promoting platelet aggregation and activation. ${ }^{43}$

Hyperglycemia in turn affects platelet and endothelial function, participating in the prothrombotic status of these patients. Protein glycation and the formation of advanced glycation end (AGE) products seem to be the underlying mechanisms. ${ }^{44}$ Endothelial alterations lead to increased production of tissue factor, ${ }^{44}$ a strong pro-coagulant, and alterations in soluble coagulation and fibrinolytic factors. Hyperglycemia provokes platelet hyperreactivity and enhanced thromboxane biosynthesis. Moreover, glycation of platelet membrane proteins may cause the enhanced expression of receptors such as P-selectin and glycoprotein IIb/IIIa, facilitating platelets interactions. Furthermore, hyperglycemia provokes nonenzymatic glycation of low density lipoprotein (LDL) and very low density lipoprotein (VLDL) which in turn may induce platelet dysfunction $^{45}$ (Table 2).

The general influence of platelets abnormalities in DM results in hypersensitivity of diabetic platelets to agonists. Indeed platelets in diabetic subjects appear to be in an activated state even in the absence of vascular injury, and respond more frequently even to subthreshold stimuli, as evidenced by greater expression of the fibrinogen-binding glycoprotein IIb/IIIa receptor, which constitutes the final common pathway of platelet activation and allows for crosslinking of individual platelets by fibrinogen molecules, and formation of thrombus. ${ }^{46}$

\section{Current antiplatelet therapy options}

The complexity of platelet activation and subsequent aggregation provides many potential sites for inhibition. Three classes of platelet-inhibiting drugs, ASA, thienopyridines and platelet glycoprotein IIb/IIIa inhibitors, are most commonly used to prevent and to treat disorders of arterial vascular thrombosis, with different mechanisms

Table 2 Insulin resistance and hyperglycemia effects on fibrinolysis, coagulation, and platelet function

\begin{tabular}{llc}
\hline Fibrinolysis & Coagulation & Platelets \\
\hline Insulin resistance & $\uparrow$ FVII, vWF, FVIII & $\downarrow$ Insulin-induced regulation \\
$\uparrow$ PAI-I & & Hyperreactivity, $\uparrow$ TX sensitivity/production \\
Hyperglycemia/AGE & $\uparrow$ TF, altered expressions FVII, FXII & HAI-I, altered balance PAI-I/tPA \\
\hline
\end{tabular}


of action. ASA inhibits thromboxane- $\mathrm{A}_{2}\left(\mathrm{TXA}_{2}\right)$ production; thienopyridines, clopidogrel and ticlopidine, antagonize ADP-induced activation; and GPIIb/IIIa receptor antagonists (abciximab, tirofiban, and eptifibatide) prevent platelet fibrinogen binding (Figure 3). The mechanism of action of ASA and thienopyridines and the role of DM in antiplatelet therapy resistance will now be discussed.

\section{Aspirin}

ASA is more than 100 years old and provides marked benefits in the primary and secondary prevention of coronary, cerebral, and peripheral vascular disease ${ }^{47} \mathrm{ASA}$ inhibits TXA 2 production by acetylating a serine residue at position 529 within the active site of the enzyme cyclo-oxygenase. ${ }^{48}$ Inhibition is irreversible and lasts for the lifespan of the platelet (7-10 days). ${ }^{49}$ The inhibition of TXA 2 production prevents $\mathrm{TXA}_{2}$-mediated granule release and aggregation, while aggregation via thromboxane- independent mechanisms, such as that induced by thrombin or elevated shear stress, can still occur. It is the first antiplatelet agent of choice for secondary prevention of ischemic events in patients with atherothrombotic disease, including patients with DM. The American Diabetes Association (ADA) recommends the use of ASA as a secondary prevention measure in diabetic patients with atherosclerotic disease. ${ }^{50}$ This recommendation is supported by data from two large meta-analyses of major secondary prevention trials by the Antithrombotic Trialists' Collaboration. ${ }^{47,51}$

The use of ASA in primary prevention in the general population is still somewhat controversial, although experts agree on its usefulness for primary prevention in patients with DM. The ADA recommends 81-325 mg/day of entericcoated ASA as a preventive strategy in high-risk diabetic individuals, defined by these risk factors: ${ }^{50}$

- family history of coronary artery disease

- cigarette smoking

- hypertension

- weight $>120 \%$ of ideal body weight

- micro- or macroalbuminuria

- total cholesterol $>200 \mathrm{mg} / \mathrm{dL}$ (LDL cholesterol $>100$, HDL cholesterol $<55$ in women and $<45$ in men, and triglycerides $>200$ )

The American Heart Association (AHA) has issued similar guidelines and recommends $75-160 \mathrm{mg} /$ day of ASA as primary prevention in high-risk individuals, defined as those with a 10 -years risk of coronary artery disease over $10 \%{ }^{52}$

The Primary Prevention Project evaluated low dose ASA $(100 \mathrm{mg} /$ day) for the prevention of cardiovascular events in almost 4500 individuals with one or more risk factors: it showed that after a mean follow-up of 3.6 years, ASA reduced the frequency of cardiovascular death and total cardiovascular events. ${ }^{53}$ In a larger population $(n=22,701)$ of healthy men including 533 diabetics, the US Physicians' Health Study found a significantly lower incidence of MI among DM subjects on ASA therapy than among those on placebo therapy. ${ }^{54}$ These results are also supported by the Early Treatment Diabetic Retinopathy Study (ETDRS), which enrolled type 1 and type 2 diabetic men and women, about $48 \%$ of whom had a history of cardiovascular disease. This study, a primary and secondary prevention trial, showed that the relative risk of MI in the first 5 years in those randomized to ASA therapy was significantly lower than those randomized to placebo. ${ }^{55}$ Finally, the Hypertension Optimal Treatment (HOT) study, which examined antihypertensive treatment in 18,790 individuals, 1501 of whom had DM, showed that ASA therapy resulted in an additional $15 \%$ reduction in the risk of cardiovascular events over that seen with antihypertensive therapy. ${ }^{56}$ These studies support the aforementioned AHA guidelines.

\section{ASA "resistance"}

Despite the use of ASA, a high percentage of patients still suffer from atherothrombotic complications, giving rise to the concept of "ASA resistance". Various studies have validated the relationship between ASA resistance and the risk of ischemic events. However, the definition of the ASA resistance phenomenon remains controversial. Strictly speaking, "resistance" is defined as the failure of a specific antiplatelet agent to inhibit its target. Thus ASA resistance should be defined as the failure of ASA to block arachidonic acid-induced platelet aggregation, inhibiting production of platelet thromboxane A2. ${ }^{57}$ In the scientific literature, the term resistance has been applied to failure to prevent occurrence of atherothrombotic vascular events in patients taking ASA (or other antiplatelet agents). However this phenomenon should more appropriately be defined as "therapeutic failure". ${ }^{58}$ Indeed numerous pathways are involved in thrombotic events, which therefore cannot be explained by inadequate inhibition of that target of an individual antiplatelet agent. Several laboratory assays have been used to explore for ASA resistance. Moreover, many of the currently available assays are also sensitive to other variables; inter-test correlations have seldom been reported, resulting in uncertainty about the capacity of these tests to detect ASA failure to the extent comparable with that of optical aggregation, considered by many experts to be the gold standard (Table 3). This uncertainty may explain why 
the reported range of ASA resistance varies broadly, from $5 \%$ to $40 \%$, depending on the assay used for identification and the population studied. ${ }^{59-61}$ Various reports have shown that when responsiveness to aASA is assessed using COX-1 specific assays, resistance to ASA is virtually absent, which is primarily the result of patient noncompliance with treatment. ${ }^{62}$ The redundancy of platelet activation pathways and receptors, not inhibited by ASA, contribute to the presence of variability of ASA-induced antiplatelet effects when using non-COX-1 specific assays. More specifically, pathways involving non-TXA $\mathrm{T}_{2}$-dependent activators such as thrombin, ADP, epinephrine, and collagen can bypass the
ASA-mediated inhibitory effect leading to platelet activation and thrombosis. ${ }^{63}$ Catecholamine-induced platelet aggregation is one such pathway that might not be adequately inhibited by ASA. Among patients with a previous MI, ASA has reportedly achieved adequate antiplatelet effects at rest, but failed to inhibit exercise-induced increases in platelet aggregation. ${ }^{64}$ Similarly, stimulation of $\mathrm{P} 2 \mathrm{Y}_{1} / \mathrm{P} 2 \mathrm{Y}_{12}$ receptors by ADP, of $\alpha_{2} \beta_{1}$ integrin and GPVI by collagen, and of PAR1/ PAR4 receptors by thrombin on platelet membrane, leads to platelet activation in spite of adequate COX-1 inhibition. ${ }^{65}$ All these pathways are increased in DM patients, because of a greater prevalence of ASA "resistance" when assessed

Table 3 Tests used to evaluate antiplatelet effect of ASA

\begin{tabular}{|c|c|c|}
\hline Test & Method & Comment \\
\hline $\begin{array}{l}\mathrm{TXB} \text { concentration in serum } \\
\text { or urine }\end{array}$ & $\begin{array}{l}\text { Measurement of serum TXB }{ }_{2} \text { or urinary } \mathrm{d}-\mathrm{TX} \mathrm{B}_{2} \\
\text { levels by radioimmunoassay or ELISA }\end{array}$ & $\begin{array}{l}\mathrm{TXA}_{2} \text { has a short half-life in serum and is rapidly } \\
\text { converted into a stable matebolite, } \mathrm{TX} \mathrm{B}_{2}\end{array}$ \\
\hline Bleeding time & $\begin{array}{l}\text { For study of the natural hemostasis; usually } \\
\text { performed with a disposable template device; the } \\
\text { test is based on the time necessary for bleeding } \\
\text { to stop following incisions in the skin of the } \\
\text { forearm }\end{array}$ & $\begin{array}{l}\text { Nonspecific and insensitive, poorly reproducible } \\
\text { and invasive; influenced by depth, location, direc- } \\
\text { tion of incisions, skin thickness, and skills } \\
\text { of the technician performing the test; rarely } \\
\text { used to assess platelet function }\end{array}$ \\
\hline
\end{tabular}

\section{Flow cytometry}

Thromboelastography

\section{Aggregometry \\ I) Classic platelet aggregometry (optical aggregation, light transmission analysis, classical turbidimetric aggregometry) \\ 2) Whole blood aggregometry}

Using antibodies, measurement of common platelet activation markers such as:

- Granule membrane markers (p-selectin, CD63, CD40L, etc)

- Activation-dependent changes in GP Ilb/llla complex conformation (PAC-I, etc)

Analysis of the clot's physical property (strength) form formation to lysis, as an agonist is added (classically arachidonic acid or adenosine diphosphate)

Analysis of light transmission as an agonist (classically arachidonic acid or adenosine diphosphate) is added to platelet rich plasma to provoke platelet aggregation

Analysis of electrical impedance between two electodes immersed in whole blood in the presence of a platelet aggregation agonist (classically arachidonic acid or adenosine diphosphate)

Assessment of platelet aggregation under high shear: whole blood is aspirated through a small aperture cut in a membrane coated with type I collagen and either epinephrine or adenosine diphosphate; the time necessary for the formation of a hemostatic plug to occlude the aperture is recorded

The test cartridge contains a preparation of human fibrinogen-coated beads and a platelet agonist; as blood is inserted into cartridge, platelet agglutinate and form aggregated, which increases light transmittance
Very powerful technique; uses whole blood, but requires expensive equipment/reagent and manipulation by experienced technician

Uses whole blood; easy and rapid to use; controversy as to correlation with classic aggregometry

Assay well estabilished in the literature; time and labor consuming, requiring manipulation of sample by an experienced technician; removal of other blood elements forbids study of their influence on platelet aggregation Used to study the influence of whole blood constituents on platelet aggregation; time consuming, requiring manipulation by experienced technicians

Intend to imitate plug formation after injury to a small vessel wall under normal flow conditions; easy and rapid to use; controversy as to correlation with classic aggregometry; very expensive

Specifically developed for the detection of platelet dysfunction in whole blood due to ASA ingestion; easy and rapid to use; controversy as to correlation with classic aggregometry; very expensive 
with non-COX-1 specific assays. ${ }^{66-68}$ The concomitant administration of commonly used analgesics may modulate the effect of low-dose ASA. A clinical dosing regimen of ibuprofen may competitively inhibit the sustained inhibitory effect of COX-1 on platelets. ${ }^{69}$ An imbalance between oxidants and antioxidants has also been suggested as an influence on aASA reactivity: Cipollone and colleagues demonstrated that increased nonenzymatic formation of isoprostanes, particularly $\mathrm{F}_{2}$-isoprostanes like 8 -iso- $\mathrm{PGF}_{2 \alpha}$, may provide an important biochemical link between an altered oxidant/ antioxidant balance and ASA-insensitive TX biosynthesis in patients with unstable angina. ${ }^{70}$

The role of genetics in a patient's response to aASA is controversial, because polymorphisms of platelet membrane glycoproteins ${ }^{71}$ of von Willebrand factor or of the collagen receptor gene have been associated with ASA resistance. ${ }^{72}$ How the concomitant presence of diabetes and these genetic polymorphisms affects the prevalence of ASA resistance remains unknown.

With all these limitations, subgroups of DM patients have been considered clinically unresponsive to the cardioprotective effects of ASA. The Heart Outcomes Prevention Evaluation trial, for example, demonstrated a 50\% higher rate of cardiovascular events in those with, compared with those without, DM despite ASA therapy. ${ }^{73}$ In the Primary Prevention Project, ASA use was not associated with cardiovascular protection in those with DM, but a $40 \%$ decrease in cardiovascular death in those without. ${ }^{74}$

\section{Thienopyridines}

Thienopyridines are orally-active antagonists of the platelet ADP $\left(\mathrm{P} 2 \mathrm{Y}_{12}\right)$ receptor. ${ }^{75}$ Clopidogrel and ticlopidine are the two currently available thienopyridines, although clopidogrel is the thienopyridine of choice because it has a more favorable safety profile than ticlopidine. ${ }^{76}$ The antiplatelet effects of thienopyridines are irreversible due to the formation of a disulfide bond with the receptor and last for the lifespan of the platelets. They are inactive prodrugs that are converted by the hepatic cytochrome P450 system into an active thiol metabolite, which interacts with the $\mathrm{P} 2 \mathrm{Y}_{12}$ receptor, in an inactive carboxy metabolite. These agents are of benefit in coronary, peripheral, or cerebrovascular atherosclerosis, and their combination with ASA is routine in patients undergoing PCI and in patients with acute coronary syndromes. ${ }^{77-79}$ Current guidelines for the management of unstable angina and non-ST elevation MI (NSTEMI) recommend promptly adding clopidogrel to ASA in patients presenting with these clinical syndromes. ${ }^{30}$ Furthermore, clopidogrel should be used in patients being treated with medical therapy or coronary revascularization for up to 9-12 months. Current guidelines also recommend administering clopidogrel to patients who are hypersensitive or intolerant to ASA. ${ }^{77}$ Clopidogrel has also been approved recently by the US Food and Drug Administration for patients with STEMI, based on the results of two large-scale clinical trials. ${ }^{77,80,81}$

The CAPRIE (Clopidogrel versus ASA in Patients at Risk of Ischemic Events) trial was a randomized, blinded trial, involving more than 19,000 patients, designed to assess the relative efficacy of clopidogrel and ASA in reducing the risk of a composite outcome cluster of ischemic stroke, MI, or vascular death. ${ }^{82}$ A retrospective analysis of the CAPRIE study showed, for the first time, the superiority of clopidogrel compared with ASA in the diabetic subgroup. This superiority was attributed to the more potent antiplatelet effect of clopidogrel, and its more efficient inhibition of hyperreactive diabetic platelets: only $15.6 \%$ of diabetic patients on clopidogrel therapy developed the composite vascular primary endpoint vs $17.7 \%$ of those on ASAtherapy alone $(p=0.042)$; the insulin subgroup showed greater absolute reduction. ${ }^{81,83,84}$

The Clopidogrel in Unstable Angina to Prevent Recurrent Events (CURE) trial evaluated the efficacy and safety of clopidogrel when given with ASA to patients suffering from acute coronary syndromes, without ST-segment elevation for 3 to 12 months $(n=12562) .{ }^{52}$ In this trial, the rate of primary outcome (composite vascular death, MI or stroke) was much higher in the diabetic cohort of patients. The use of clopidogrel in this subgroup reduced the rate of this endpoint (14.2\% rate of primary end-point in diabetic cohort on clopidogrel vs $16.7 \%$ in diabetic cohort on placebo) without it reaching statistical significance. ${ }^{79}$ The high event rates may in part be attributed to the persistence of increased platelet reactivity in DM patients even when on dual antiplatelet therapy compared with non-DM patients.

\section{Clopidogrel response variability}

The methodology most commonly reported in the literature to measure clopidogrel response is conventional light transmittance aggregometry, in which platelet-rich plasma is prepared from blood usually anticoagulated with citrate and then stimulated with ADP. ${ }^{85}$ Notably, the degree of platelet responsiveness in patients treated with clopidogrel has been found to follow a normal bell curve. ${ }^{85,86}$ The concept of variability in response to clopidogrel has long been recognized during investigations of platelet reactivity, especially after elective coronary stent implantation. ${ }^{87}$ Several studies investigated the use of a $300 \mathrm{mg}$ loading dose of clopidogrel 
immediately after stenting and found highly variable responses among individuals. ${ }^{88-90}$ Although higher loading dose regimens are associated with better and faster response profiles, a broad variability in the antiplatelet effects continues to be observed. ${ }^{91,92}$ The durability of platelet inhibition by clopidogrel has also been studied showing the sustained antiplatelet effect of clopidogrel after 5 days, but also a significant heterogeneous response to the medication. ${ }^{93}$ Thus the antiplatelet effects after both the acute and chronic phases of clopidogrel therapy vary. ${ }^{86}$ Importantly, increased rates of coronary stent thrombosis and recurrent ischemic events after PCI, have been noted in poor clopidogrel responders. Variability in clopidogrel response is a multifactorial process, in which clinical, cellular, and genetic factors are involved. ${ }^{86}$ Among the clinical factors, DM has been associated with a greater prevalence of poor responsiveness. ${ }^{16}$ In particular, diabetic patients have been shown to have a poor response to clopidogrel in both the acute and chronic phases of therapy. ${ }^{67}$ Of note, insulin-requiring diabetics are those who persist with the strongest platelet reactivity despite dual antiplatelet therapy. ${ }^{23} \mathrm{DM}$ patients usually have a poor response to dual antiplatelet therapy, but a variety of antiplatelet effects has also been observed in these patients. ${ }^{67}$ Recent findings have shown that enhanced platelet reactivity selectively determined in DM patients, enables identification of those with a greater long-term risk of atherothrombotic events. ${ }^{19}$

Overall, the persistence of elevated platelet reactivity, and reduced response to ASA and clopidogrel therapy, enhance the atherothrombotic risk of DM patients. Multiple causes have been suggested. Poor glycemic control is an important cause of increased platelet reactivity ${ }^{18,23,94}$ In this way, platelet reactivity can be reduced with tight control of glucose levels. ${ }^{95}$ Other mechanisms intrinsic to the diabetic platelet, which involve intracellular signaling pathways, play a critical role in platelet reactivity. These may include increased oxidative stress leading to enhanced peroxidation of arachidonic acid to form biologically active isoprostanes, ${ }^{18}$ increased platelet turnover, ${ }^{67}$ increased cytosolic levels of calcium, ${ }^{96,97}$ insulin resistance, and upregulation of the $\mathrm{P} 2 \mathrm{Y}_{12}$ pathway. ${ }^{67,98}$

\section{Treating ASA and clopidogrel resistance}

The treatment for failed antiplatelet therapy, especially in diabetic patients, is as yet undefined. Initially, physicians should ensure patient compliance, and minimize drug-drug interactions. In diabetic patients, physicians must also establish optimal control of glucose levels, cholesterol levels, and blood pressure, thus minimizing platelet reactivity.
The optimal dose is controversial. There is no good evidence to date that increasing the ASA dose would be useful, especially because of an increased risk of bleeding. ${ }^{99}$ Of note, increasing the dose of ASA is not associated with further inhibition of COX-1. ${ }^{99}$ Increasing the loading or maintenance doses of clopidogrel may be an option. ${ }^{25,99}$ Increasing the loading dose increases drug responsiveness and has been associated with improved clinical outcomes. ${ }^{100,101}$ This approach is valid only for the acute phase of treatment, however, because patients must rely on daily maintenance therapy for long-term prevention of ischemic events. The Optimizing Antiplatelet Therapy in Diabetes Mellitus (OPTIMUS) study evaluated the functional impact of a 150-mg maintenance dose of clopidogrel compared with a standard 75-mg dose selectively in type $2 \mathrm{DM}$ patients with a suboptimal response to standard dose therapy. High maintenance therapy was associated with enhanced antiplatelet effects compared with the 75-mg dose. ${ }^{25}$ Although a high dose resulted in marked platelet inhibition, many patients remained above the therapeutic threshold of post-treatment platelet reactivity used in this study, suggesting the need for alternative antithrombotic regimens in these high-risk patients. This issue has prompted recent interest in triple antiplatelet therapy in DM patients, using cilostazol in addition to ASA and clopidogrel. Triple therapy has been shown to be associated with a reduced risk of stent thrombosis. ${ }^{102,103}$ In the bare metal stent (BMS) era, triple therapy was shown to be beneficial for high risk patients, including diabetics, in reducing restenosis rates. ${ }^{102}$ In the DES era, recent findings from the DECLARE-DIABETES study showed triple therapy to be associated with reduced target lesion revascularization (TLR) and major adverse cardiac events (MACE) at 9 months. ${ }^{104}$ The mechanisms underlying this benefit may arise from the greater antiplatelet effects achieved, as well as the effects of cilostazol on endothelial cells and smooth vascular muscle cells. The OPTIMUS-2 study evaluated the functional impact of adding cilostazol to ASA and clopidogrel therapy in type 2 DM patients. The study showed that cilostazol compared with placebo was associated with marked inhibition of $\mathrm{P} 2 \mathrm{Y}_{12}$ signaling. ${ }^{105}$ Current guidelines specify a class IIb indication with a level of evidence $\mathrm{C}$ that the dose of clopidogrel can be increased to $150 \mathrm{mg}$ per day if $<50 \%$ inhibition of platelet aggregation is demonstrated only in patients in whom stent thrombosis may be catastrophic or lethal (such as unprotected left main, bifurcating left main and last patent coronary vessel). ${ }^{106}$ However, although the use of a $150-\mathrm{mg}$ maintenance dose of clopidogrel in patients with type $2 \mathrm{DM}$ and with $<50 \%$ platelet inhibition has been 
shown to be associated with enhanced antiplatelet effects, these effects are nonuniform and many patients persist with inadequate platelet inhibition. ${ }^{107}$ Probably the use of more potent $\mathrm{P} 2 \mathrm{Y}_{12}$ inhibitors, with their uniform and potent effect, could help us resolve this problem. Prasugrel is a thirdgeneration $\mathrm{P}_{2} \mathrm{Y}_{12}$ inhibitor, with more potent and less variable antiplatelet effects compared with clopidogrel. ${ }^{108,109}$ Recently, the TRITON-TIMI 38 (Trial to Assess Improvement in Therapeutic Outcomes by Optimizing Platelet Inhibition with Prasugrel-Thrombolysis in Myocardial Infarction) trial showed significantly reduced rates of ischemic events, including stent thrombosis, in patients presenting with acute coronary syndromes undergoing PCI treated with prasugrel compared with clopidogrel. ${ }^{110}$ The net clinical benefit achieved with prasugrel in the general study population still has statistical significance for better clinical outcomes although diminished by an increased risk of bleeding. Importantly, in this trial the greatest risk reduction (rate of primary end-point, defined as death from cardiovascular causes, nonfatal MI or nonfatal stroke, in diabetic patients on prasugrel $12.2 \%$ vs diabetic patients on clopidogrel $17.0 \%$ with $30 \%$ relative risk reduction) was observed in the diabetic population $(n=3146)$. Importantly, in these patients prasugrel was not associated with an increased risk of major bleedings compared with clopidogrel. The functional impact of prasugrel vs clopidogrel among selected diabetic patients is currently being evaluated in the OPTIMUS-3 study.

\section{Percutaneous coronary revascularization in diabetics}

Diabetic patients have more progressive, diffuse, and multivessel coronary disease compared with nondiabetics, ${ }^{111,112}$ and have been shown to have worse outcomes after both PCI, especially with BMS, and surgery, compared with nondiabetic patients. ${ }^{113}$ This prognosis includes a $35 \%$ to $45 \%$ higher incidence of TLR and a $33 \%$ to $86 \%$ higher incidence of angiographic restenosis compared with nondiabetic patients with BMS. ${ }^{113,114}$ The advent of DES has completely changed the scenario of percutaneous revascularization in diabetic patients. Most clinical experience with DES comes from the Cypher ${ }^{\circledR}$ (sirolimus) and Taxus ${ }^{\circledR}$ (paclitaxel) stents, introduced in 2002 and 2003, respectively. Compared with BMS, the first generation DES significantly reduced restenosis rates and MACE, and show significantly lower rates of TLR, target vessel revascularization (TVR) and target vessel failure (TVF). ${ }^{8,115}$

Despite the routine use of DES in diabetic patients, only limited data are available for systematic evaluation of their long term safety in this population. Most of the data come from published subgroup analysis of randomized trials between DES and BMS, and registry data from single or multiple centers. ${ }^{115}$ Five studies, that is, DIABETES, ${ }^{116}$ ISAR-DIABETES, ${ }^{117}$ a recently published head-to-head comparison of sirolimus-eluting stent (SES) and paclitaxel (PES)-eluting stent in 120 diabetics patients, ${ }^{118}$ the SCORPIUS Trial, ${ }^{119}$ and the DESSERT Study, ${ }^{120}$ focused solely on diabetics (Table 4).

The DIABETES ${ }^{116}$ (Diabetes and Sirolimus-Eluting Stent) trial is a multicenter, randomized, placebo-controlled trial involving 160 diabetic patients, 80 of whom were treated with BMS and 80 with SES. Late lumen loss (LLL) assessed by QCA at 9 month follow-up was the primary end-point. The SES treated group showed a significant reduction of LLL (relative reduction 87\%). The study considered a subrandomization according to the type of diabetes; the SES benefit was independent from diabetes status. The study also demonstrated similar repeat revascularization rates among both insulin- and noninsulin-treated diabetics; and confirmed the relationship between glycemic control and progression of atherosclerosis. These results with SES have recently been confirmed by two trials especially designed for diabetic patients: the SCORPIUS Trial ${ }^{119}$ and the Italian Multicenter Randomized DESSERT Study. ${ }^{120}$

The ISAR (In-Stent Angiographic Restenosis)DIABETES $^{117}$ a prospective trial, was designed to show the noninferiority of the PES compared with SES, defined as a difference in the extent of in-segment LLL of no more than $0.16 \mathrm{~mm}$, at 6-8 months follow-up. The study included 250 diabetic patients randomized to receive SES $(n=150)$ or PES ( $n=150)$. It found that the use of SES in diabetics was associated with a decrease in the extent of late loss, in insulin-treated $(p=0.02)$ and noninsulin-treated $(p=0.03)$ patients, suggesting a reduced risk of restenosis, but the study was not sufficiently powered to assess the incidence of clinical restenosis.

Tomai and colleagues compared the efficacy of SES and PES in diabetic patients with multiple de novo coronary artery lesions, to prevent restenosis. ${ }^{118}$ They randomized 60 patients for a total of 120 lesions (SES, $n=60 ;$ PES, $n=60$ ) and concluded that SES, when directly compared with PES, is associated with a decrease in the extent of in-stent LLL at 8 months, suggesting a reduced risk of restenosis.

Although DES reduces angiographic and clinical restenosis compared with BMS, in late 2006 concerns over DES safety emerged. Several studies and meta-analysis suggested increases in adverse clinical end-points with DES, especially after the first year of stent implantation. ${ }^{121,122}$ The overall rate of acute and subacute ST (occurring within 24 hours or within 30 days after stent implantation respectively) appears to be 
no different for DES and BMS, but analysis incorporating long-term follow-up has shown a small but finite risk of late ST associated with DES. Of note, despite the small increase in late ST, overall rates of death and MI are similar between DES and BMS. ${ }^{121-124}$ The magnitude of very late ST is not well defined, but is in the range of $0.2 \%-0.4 \%$ excess events per year after year 1 through year $4 .{ }^{125,126}$ Importantly, these numbers are from clinical trials and not from real world practice, where patients show more complex scenarios.

Surgery remains the gold standard treatment for multivessel disease in diabetics. The ongoing CARDIA (Coronary Artery Revascularization in DIAbetes) trial ${ }^{127}$ and the FREEDOM (Future REvascularization Evaluation in Patients with Diabetes mellitus: Optimal management of Multivessel disease) trial ${ }^{128}$ will shed light on the outcomes of DES implantation in diabetics compared with current surgical techniques.

\section{Stent thrombosis in diabetics: incidence and predictors}

ST with BMS and DES often presents in a catastrophic way, by triggering death or acute MI. ${ }^{3,129}$ The incidence of ST could easily be underestimated, because a patient's cause of death is not always determined and angiography is not always performed after MI. To control for this possibility, cases in which patients have experienced sudden death or acute MI not definitively proved to be secondary to ST have been adjudicated judged as thrombotic events in studies examining incidence and predictors of ST. ${ }^{3,129}$ The Academic Research Consortium ${ }^{130}$ developed consensus definitions delineating 3 levels of certainty of ST: definite, probable, and possible. Definite ST involves the pathologic or angiographic confirmation of thrombus within a stent in a patient who presents with an acute coronary syndrome. Probable ST pertains to any unexplained death within 30 days after PCI or any target-vessel acute MI occurring without angiographic confirmation of a culprit lesion. Possible ST includes any unexplained death occurring later than 30 days after the index procedure (Table 5). ST is also classified according to time of presentation. Acute ST appears within 24 hours after PCI; subacute ST presents between 24 hours and 30 days; late ST between 1 and 12 months; very late ST occurs later than 1 year.

Table 4 Studies performed in diabetic patients treated with DES

\begin{tabular}{|c|c|}
\hline Study & Design and results \\
\hline Diabetes $^{117}$ & $\begin{array}{l}\text { I } 60 \text { DM patients: } 80 \text { BMS } \\
\qquad 80 \text { SES. } \\
\text { Primary end point: LLL at } 9 \text { month } \\
\text { In-segment LLLwas reduced from } 0.470 .5 \mathrm{~mm} \text { for BMS to } 0.060 .4 \mathrm{~mm} \text { for SES(P } 0.00 \mathrm{I}) \text {. } \\
\text { TLR and MACE: } 31.3 \% \text { and } 36 \% \text { in BMS versus } 7.3 \% \text { and I I.3\% in SES; both } P \text { 0.00I). } 9 \text {-month follow-up } \\
\text { ST occurred in } 2 \text { BMS patients } \\
\text { No ST in SES group }\end{array}$ \\
\hline ISAR-DIABETES ${ }^{18}$ & $\begin{array}{l}250 \text { DM patients: I50 SES } \\
\qquad 150 \text { PES } \\
\text { Noninferiority of the PES vs SES: } \\
\text { Primary end point: difference in LLL of no more than } 0.16 \mathrm{~mm} \text {, at } 6-8 \text { months follow-up. } \\
\text { SES associated with a decrease in the extent of LLL in insulin-treated }(p=0.02) \text { and noninsulin-treated } \\
(p=0.03) \text { patients. }\end{array}$ \\
\hline $\begin{array}{l}\text { Tomai and } \\
\text { colleagues }^{119}\end{array}$ & $\begin{array}{l}60 \text { DM patients, } 120 \text { lesions: } 60 \text { SES, } \\
\qquad 60 \text { PES, } \\
\text { SES associated with a decrease in the extent of in-stent LLL at } 8 \text { months, suggesting a reduced risk of } \\
\text { restenosis. }\end{array}$ \\
\hline SCORPIUS'120 & $\begin{array}{l}200 \text { DM patients : } 98 \text { SES } \\
\qquad 102 \text { BMS } \\
\text { Primary end point: in segment LLL. Secondary: MACE rate at } 30 \text { days and } 8 \text { and } 12 \text { months. LLL in SES was } \\
0.18 \mathrm{~mm} ; 0.74 \mathrm{~mm} \text { in BMS. In-segment restenosis: } 8.8 \% \text { SES and } 42.1 \% \text { BMS ( }<0.0001) \text {.TLR: } 5.3 \% \text { in SES } \\
\text { and in } 21.1 \% \text { in BMS ( } p=0.002) \text { MACE rate } 14.7 \% \text { in SES versus } 35.8 \% \text { in BMS. }\end{array}$ \\
\hline DESSERT $^{|2|}$ & 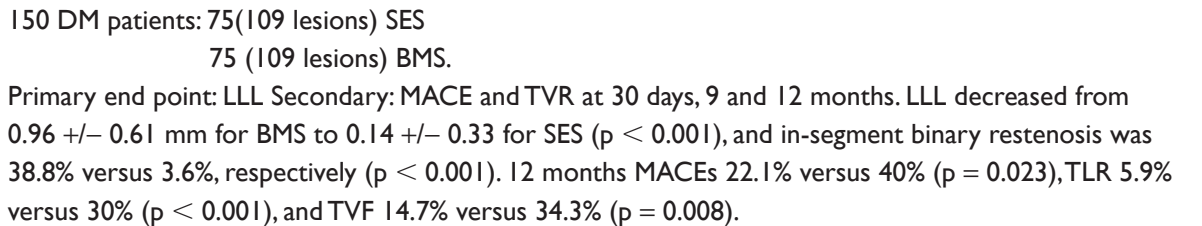 \\
\hline
\end{tabular}




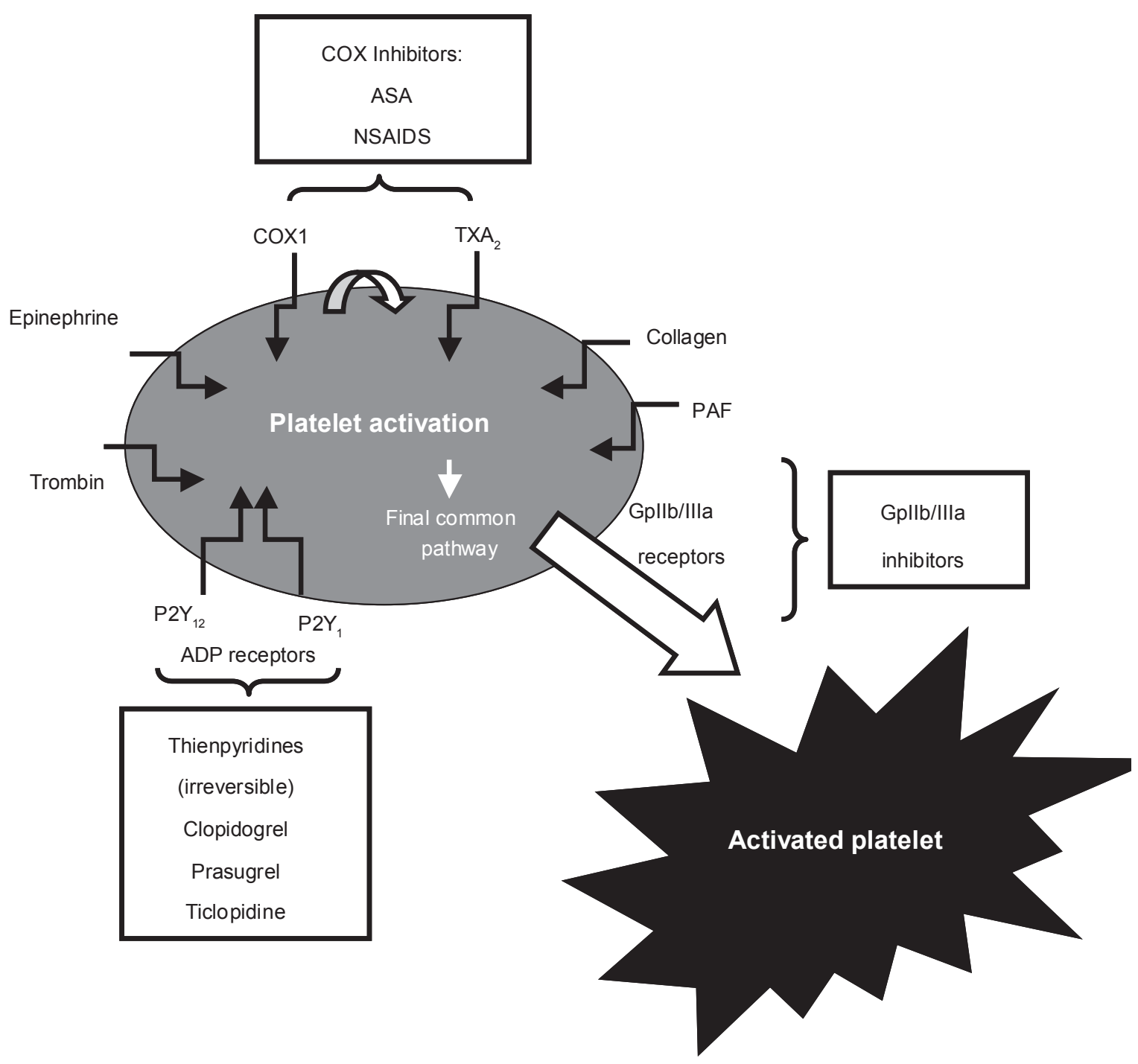

Figure 3 Pathways of platelet activation and mechanism of action of antiplatelet agents.

Abbreviations: ASA, acetylsalycilic acid; NSAIDs, nonsteroidal anti-inflameates inhibitors; PAF, platelet-activating factor; TXA ${ }_{2}$, thromboaxane- $A_{2}$.

Table 5 Academic research consortium definitions of stent thrombosis

Category Definition

\section{Definite}

Probable

Possible
I. Angiographic confirmation based on Thrombolysis in Myocardial Infarction (TIMI) flow and I of the following within 48 hours:

- New acute onset of ischemic symptoms at rest

- New ischemic electrocardiographic changes suggestive of acute ischemia

- Typical increase and decrease in cardiac biomarkers as evidence of an acute myocardial infarction (MI)

2. Pathologic confirmation of recent ST at autopsy or by tissue examination after thrombectomy

I. Any unexplained death within the first 30 days

2. MI related to acute ischemia in the territory of the implanted stent without angiographic confirmation of ST and in the absence of any other obvious cause at any time after index procedure

Any unexplained death after intracoronary stenting from 30 days after index percutaneous coronary intervention until the end of trial follow-up 
A number of factors are associated with DES thrombosis. In a series of 2,229 patients, of whom 29 experienced ST, risk factors included bifurcation lesions, renal failure, PCI in the setting of acute MI and DM. ${ }^{129}$ The strongest association was between ST and the premature discontinuation of clopidogrel. The etiology of ST is multifactorial. ${ }^{131}$ Patient, lesion, procedural, and stent characteristics can all play a role. Other factors include mechanisms unique to the DES, namely, hypersensitivity, inflammatory responses, and delayed endothelialization. ${ }^{132}$ Given that these reactions occur predominantly with late ST, the presumed trigger is hypersensitivity to the stent polymer, because active drug should no longer be present. This phenomenon has not been documented with BMS.

The increased risk in diabetic patients might be related to the pro-inflammatory and pro-thrombotic status typical of this population along with the more diffuse and aggressive nature of atherosclerosis (longer lesion lengths, smaller vessel size, and greater plaque burden) which might lead to less optimal procedural results. ${ }^{8,133-135}$

The nonresponsiveness to antiplatelet therapy also has a role: diabetics have been considered clinically unresponsive to the cardioprotective effects of ASA and clopidogrel. ${ }^{16}$ Patients with ST have high in vitro post-treatment platelet reactivity despite the dual antiplatelet treatment, suggesting that platelet aggregation nonresponsiveness to clopidogrel may be an important cause. ${ }^{136}$ Buonamici and colleagues ${ }^{137}$ assessed whether nonresponsiveness to clopidogrel as revealed by high in-vitro post-treatment platelet reactivity was predictive of DES thrombosis. In their interesting work, a total of 804 patients who had successful SES or PES implantation were assessed for post-treatment platelet reactivity after a loading dose of $600 \mathrm{mg}$ of clopidogrel. Patients with platelet aggregation by $10 \mu \mathrm{mol}$ adenosine 5-diphosphate $\geq 70 \%$ were defined as nonresponders. All patients received chronic dual antiplatelet treatment (ASA $325 \mathrm{mg}$ and clopidogrel $75 \mathrm{mg}$ daily) for 6 months. The primary end-point was the incidence of definite/probable early, subacute, and late ST at 6-month follow-up. The incidence of 6-month definite/probable ST was 3.1\% (Table 6).

Table 6 ST classification according to time of presentation

\begin{tabular}{ll}
\hline Acute & $<24 \mathrm{hr}$ \\
Subacute & $>24 \mathrm{hr}<30$ days \\
Late & $>30$ days $<12$ months \\
Very late & $>12$ months \\
\hline
\end{tabular}

All ST were subacute or late. Of 804 patients, 105 (13\%) were not responsive to clopidogrel. The incidence of ST was $8.6 \%$ in nonresponders and $2.3 \%$ in responders $(\mathrm{p}<0.001)$. The authors concluded that nonresponsiveness to clopidogrel is a strong independent predictor of ST in patients receiving SES or PES. Moreover in this study, DM was associated with low response (overall 169 DM patients: 19\% were responders and $36 \%$ nonresponders, $\mathrm{p}>0.001$ ).

To date, few large-scale studies have focused on very late ST, later than 1 year after DES implantation. Specific predictors for late ST have not yet been identified. Moreover, DES thrombosis in randomized trials could not be comparable to those observed in clinical practice, frequently including off-label indications. Interestingly the Multicenter Spanish Registry ESTROFA ${ }^{138}$ was designed to assess the incidence, predictors, and outcome of DES thrombosis (angiographydocumented) in real-world clinical practice, with 3 years follow-up. In a total of 23,500 patients treated with DES the cumulative incidence of ST was $2 \%$ at 3 years. Antiplatelet treatment had been discontinued in 95 cases $(31.6 \%)$. No differences in incidences were found among stent types. Independent predictors for subacute ST analyzed in a subgroup of 14,120 cases were diabetes, renal failure, acute coronary syndrome, STEMI, stent length, and left anterior descending artery stenting; while predictors for late ST were STEMI, stenting in left anterior descending artery, and stent length. The authors concluded that patient profiles differed between early and late ST.

Daemen and colleagues ${ }^{121}$ performed a large multicenter cohort study assessing all angiographically documented ST, after unrestricted use of SES and PES (8146 patients; SES $\mathrm{n}=3823$; PES $\mathrm{n}=4323$ ) between 2002 and 2005. Their purposes were to estimate the incidence and time course of ST with DES in routine clinical practice; identify predictors and differences between early ( $<30$ days) and late ( $>30$ days) ST; and assess differences between SES and PES. They observed angiographically documented ST in 152 patients (cumulative incidence at 3 years $2.9 \%$ ). Early ST was noted in $91(60 \%)$ patients, and late ST in $61(40 \%)$ patients. Late ST occurred steadily at a constant rate of $0.6 \%$ per year up to 3 years after stent implantation. Incidence of early ST was similar for SES (1.1\%) and PES (1.3\%), but late ST was more frequent with PES (1.8\%) than with SES $(1.4 \% ; p=0.031)$. At the time of ST, dual antiplatelet therapy was being taken by $87 \%$ (early) and $23 \%$ (late) of patients ( $p<0.0001)$. Independent predictors of overall ST were acute coronary syndrome at presentation (HR 2.28, 95\% CI $1.29-4.03)$ and diabetes $(2.03,1.07-3.83)$. The results of the 
present study suggest that late ST with DES occurs more frequently than expected ${ }^{116}$ and that rates increase steadily during long-term follow-up. The authors suggest that sustained occurrence over a long-term period might be explained in part by the delayed healing response after implantation of DES. This maybe due to the delayed re-endothelization and hypersensitivity reactions to the antiproliferative drugs, or more probably, to the synthetic polymers. ${ }^{131,132}$ This study confirms the predictive value of diabetes and acute coronary syndrome at presentation.

A specific assessment of DES safety in DM has yet to be demonstrated. Whether DES are similarly safe and effective in the higher risk cohort of diabetic patients remains controversial. Several meta-analysis and registries have been performed showing contrasting data.

Kumbhan and colleagues ${ }^{139}$ conducted a meta-analysis including randomized trials comparing either PES or SES with a BMS or PES with SES, in diabetic patients during a follow-up of a maximum of 12 months. A total of 16 studies were identified, which included 2951 diabetic patients. A reduction in target lesion revascularization (TLR) was found with DES compared with BMS (RR 0.35, 95\% CI $0.27-0.46, \mathrm{P}<0.001)$. Similar reductions were noted in the incidence of MACE (RR $0.42,95 \%$ CI $0.31-0.56$, $\mathrm{P}<0.001$ ), in-segment restenosis (RR $0.31,95 \%$ CI $0.25-0.40, \mathrm{P}<0.001$ ), and non-Q-wave MI (RR 0.57, $95 \%$ CI 0.32-0.99, $\mathrm{P}=0.046)$. Event rates were similar for Q-wave MI (RR 0.72, 95\% CI 0.25-2.07, P = 0.54), death (RR 0.64, 95\% CI 0.32-1.28, P = 0.20), and ST (RR 0.41, $95 \%$ CI $0.13-1.27, \mathrm{P}=0.12$ ).

The specific safety of SES compared with BMS has been addressed in a recent meta-analysis by Spaulding and colleagues. ${ }^{140}$ The authors reported greater long-term mortality in patients with DM treated with SES compared with those treated with BMS, an effect that was absent in patients without DM. These data must be interpreted with caution: in the studies analyzed, survival among BMS treated patients was far better than expected, which may have accounted for the observed differences. Besides, spurious results due to the modest-sized diabetic cohort $(n=428)$ in this series may be another cause of error. On the other hand, the analysis of 1-year data collected by the e-Cypher registry ${ }^{141}$ suggests a high degree of safety of SES, with a rate of ST similar to that observed in randomized trials. Insulin treated DM among other factors was recognized as a clinical predictor of stent thrombosis at 12 months.

The EVASTENT Matched-Cohort Registry ${ }^{142}$ assessed the frequency and causes of ST specifically in diabetic and nondiabetic patients after SES implantation. In this matched multicenter cohort registry of 1731 during a 1-year followup, MACE occurred in 78 patients $(4.5 \%)$, cardiac death in 35 (2.1\%), and stent thrombosis in 45 (2.6\%): 30 definite, 23 subacute, and 22 late, including 9 at 6 months. In univariate analysis, the 1-year ST rate was 1.8 times higher in diabetic than in nondiabetic patients (3.2\% vs $1.7 \%$; log rank $\mathrm{p}<0.03$ ); diabetic patients with multivessel disease experienced the highest rate and nondiabetic single-vessel disease patients the lowest ( $4.3 \%$ vs $0.8 \% ; p<0.001)$. In multivariate analysis, in addition to the interruption of antithrombotic treatment, independent ST predictors were previous stroke, renal failure, lower ejection fraction, calcified lesion, length stented, and insulin-requiring diabetes.

The safety of PES vs BMS has also been assessed. Analysis of the five pivotal PES trials focused specifically on the diabetic patient ${ }^{143}$ demonstrated similar rates of death, MI, and ST with both stents at 4-year follow-up. Patients treated with PES and BMS had similar baseline characteristics among both the diabetic and nondiabetic cohorts in these trials. At 4-year follow-up, there were no significant differences between PES and BMS among diabetic patients in the rates of death $(8.4 \%$ vs $10.3 \%$, respectively, $p=0.61)$, MI $(6.9 \%$ vs $8.9 \%, p=0.17)$, or ST $(1.4 \%$ vs $1.2 \%, p=0.92)$. ST was adjudicated by the Academic Research Consortium (ARC) as not being restricted to the angiographically determined events. Treatment of diabetic patients with PES compared with BMS was associated with a significant and durable reduction in TLR over the 4-year follow-up period $(12.4 \%$ vs $24.7 \%, \mathrm{p}<0.0001)$. The relative safety and efficacy of PES compared with BMS in diabetic patients extended to both those requiring and not requiring insulin. The rates of both efficacy and safety end-points may vary in a less selected patient population in which stents are implanted in more complex and higher-risk situations. Frequent scenarios in DM patients are: true bifurcation lesions, multivessel disease, and acute MI. Interestingly, Kuchulakanti and colleagues ${ }^{144}$ assessed the correlates and outcomes of angiographically proven ST with DES (PES and SES) in a population of 2974 consecutive patients. Compared with patients without ST, patients with ST had a higher frequency of diabetes, acute post-procedural renal failure, and chronic renal failure. There were more bifurcation lesions, type C lesions, and a trend for smaller-diameter stents. Discontinuation of clopidogrel was more frequent in these patients ( $36.8 \%$ vs $10.7 \% ; \mathrm{p}=0.0001)$. The author stressed that careful management is warranted in patients with renal failure and in those undergoing treatment for in-stent 
restenosis and bifurcations. These data reflect outcomes from a real world population. Specific and sufficiently powered, well-defined, randomized studies are needed to understand the real safety of DES in DM.

\section{Clinical and therapeutic implications}

The concern of late ST has emerged with the widespread use of DES, during the last 5 years. To date long-term safety has not been addressed in a powered, randomized trial, specifically designed for diabetic patients. These aforementioned studies, and meta-analysis results, seem to minimize the problem, showing similar rates of late ST, but these data must be interpreted with caution for many reasons. The heterogeneity and end-point definitions differed among the pooled trials; diabetic patients were often a subgroup in the study population because these trials were not designed to study diabetics exclusively. Because original data were not accessed, no information on patient glycemic control was available, and discrepancies arising from variability in the definition of diabetes, and ST, could not be resolved.

Available data so far show that diabetes is an independent predictor of ST; despite the use of dual antiplatelet therapy, patients with DM have a higher risk of developing adverse clinical outcomes. Recent observations suggest that this risk may relate to platelet dysfunction typical of DM, leading to inadequate platelet inhibition.

Research results in general imply a complex and multidisciplinary treatment for this type of patient. When PCI is indicated for a diabetic patient, DES is the device of choice. At the same time, tight glycemic control and compliance with guidelines for antiplatelet drug management are mandatory. A specific antiplatelet regimen in DM may be useful. Novel antiplatelet agents with a strong action against the hyperactivated "diabetic platelet" may be needed.

\section{Conclusions}

Coronary revascularization in diabetic patients remains a challenge. The introduction of DES has improved PCI outcomes, but the problem of atherothrombotic complications, including ST, persist for which DM is recognized as an independent predictor. Inadequate responsiveness to currently available antiplatelet agents, including ASA and clopidogrel, may contribute to these poor outcomes. Novel antiplatelet agents under advanced clinical investigation may provide future treatment alternatives to tackle the "diabetic platelet". Indeed, dedicated studies on selected diabetic patients are warranted, to understand the real magnitude and significance of the problem, and find an appropriate solution.

\section{Disclosure}

The authors report no conflicts of interest in this work.

\section{References}

1. Mc Fadden EP, Stabile E, Regar E, et al. Late thrombosis in drugeluting stent after discontinuation of antiplatelet therapy. Lancet. 2004;364:1519-1521.

2. Moreno R, Fernandez C, Hernandez R, et al. Drug-eluting stent thrombosis: results from a pooled análisis including 10 randomized studies. J Am Coll Cardiol. 2005;45:954-959.

3. Iakovou I, Schmidt T, Bonizzoni E, et al. Incidence, predictors, and outcome of thrombosis after successful implantation of drug-eluting stents. JAMA. 2005;293:2126-2130.

4. Ong AT, McFadden EP, Regar E, de Jaegere PP, van Domburg RT, Serruys PW. Late angiographic stent thrombosis (LAST) events with drug-eluting stents. J Am Coll Cardiol. 2005;45:2088-2092.

5. Steinhubl SR, Berger PB, Mann JTI, Fry ET, DeLago A. Early and sustained dual oral antiplatelet therapy following percutaneous coronary intervention: a randomized controlled trial. JAMA. 2002;288:2411-2420.

6. Cheneau E, leborgne L, Mintz GS, Kotani J, Pichard AD, Satler LF, Canos D, Castagna M, Weissman NJ, Waksman R. Predictors of subacute stent thrombosis: results of a systematic intravascular ultrasound study. Circulation. 2003;108:43-47.

7. Fujii K, Carlier SG, Mintz GS, et al. Stent underexpansion and residual reference segment stenosis are related to stent thrombosis after sirolimus-eluting stent implantation: an intravascular ultrasound study. J Am Coll Cardiol. 2005;45:995-998.

8. Cola C, Sabaté M. Revascularization in high risk patients: diabetes mellitus. Minerva Cardioangiol. 2007;55:557-577.

9. Gurbel PA, Callahan KP, Malinin AI, Serebruany VL, Gillis J. Could stent design affect platelet activation? Results of the Platelet Activation in STenting (PAST) study. J Invasive Cardiol. 2002;14:584-589.

10. Nebeker JR, Virmani R, Bennett CL, et al. Hypersensitivity cases associated with drug-eluting coronary stents: a review of available cases from the Research on Adverse Drug Events and reports (RADAR) project. J Am Coll Cardiol. 2006;47:175-181.

11. Steffel J, Latini RA, Akhmedov A, et al. Rapamycin, but not FK-506, increases endothelial tissue factor expression: implications for drugeluting stent design. Circulation. 2005;112:2002-2011.

12. Stahli BE, Camici GG, Steffel J, et al. Paclitaxel enhances thrombininduced endothelial tissue factor expression via c-Jun terminal $\mathrm{NH}_{2}$ kinase activation. Circ Res. 2006;99:149-155.

13. Finn AV, Kolodgie FD, Harnek J, et al. Differential response of delayed healing and persistent inflammation at sites of overlapping sirolimus- or paclitaxel-eluting stents. Circulation. 2005;112:270-278.

14. Matter CM, Rozenberg I, Jaschko A, et al. Effect of tacrolimus or sirolimus on proliferation of vascular smooth muscle and endothelial cells. J Cardiovasc Pharmacol. 2006;48:286-292.

15. Park DW, Park SW, Park KH, et al. Frequency of and risk factors for stent thrombosis after drug-eluting stent implantation during long-term follow-up. Am J Cardiol. 2006;98:352-356.

16. Angiolillo DJ. Antiplatelet therapy in type 2 diabetes mellitus. Curr Opin Endocrinol Diabetes Obes. 2007;14:124-131.

17. Vinik A, Erbas T, Sun Park T, Nolan R, Pittenger G. Platelet dysfunction and type II diabetes. Diabetes Care. 2001;24:1476-1485.

18. Ferroni P, Basili S, Falco A, Davì G. Platelet activation in type 2 diabetes mellitus. J Thromb Haemost. 2004;2:1282-1291.

19. Angiolillo DJ, Bernardo E, Sabate M, et al. Impact of platelet reactivity on cardiovascular outcomes in patients with type 2 diabetes mellitus and coronary artery disease. $\mathrm{J} \mathrm{Am} \mathrm{Coll} \mathrm{Cardiol.}$ 2007;50:1541-1547.

20. Watala C, Golanski J, Pluta J, et al. Reduced sensitivity of platelet from type 2 diabetic patients to acetylsalicylic (aspirin)-its relation to metabolic control. J Thromb Res. 2004;113:101-113. 
21. Mori TA, Vandongen R, Douglas AJ, McCulloch RK, Burke V. Differential effect of aspirin on platelet aggregation in IDDM. Diabetes. 1992;41:261-266.

22. Angiolillo DJ, Fernandez-Ortiz A, Bernardo E, et al. Influence of aspirin resistance on platelet function profiles in patients on long-term aspirin and clopidogrel after percutaneous coronary internvention. Am J Cardiol. 2006;97:38-43.

23. Angiolillo DJ, Bernardo E, Ramirez C, et al. Insulin therapy is associated with platelet dysfunction in patients with type 2 diabetes mellitus on dual oral antiplatelet treatment. J Am Coll Cardiol. 2006;48:298-304.

24. Angiolillo DJ, Fernandez-Ortiz A, Bernardo E, et al. Clopidogrel responders and interindividual variability in platelet inhibition following a high clopidogrel loading dose regimen during coronary intervention. Eur Heart J. 2004;25:1903-1910.

25. Angiolillo DJ, Shoemaker SB, Desai B, et al. Randomized comparison of a high clopidogrel maintenance dose in patients with diabetes mellitus and coronary artery disease. Circulation. 2007;115:708-716.

26. King H, Aubert RE, Herman WH. Global burden of diabetes, 1995-2025: prevalence, numerical estimates, and projections. Diabetes Care. 1998;21:1414-1431.

27. Nathan DM. Long-term complications of diabetes mellitus. $N$ Engl J Med. 1993;328:1676-1685.

28. Brand FN, Abbott RD, Kannel WB. Diabetes, intermittent claudication, and risk of cardiovascular events. Diabetes. 1989;38:504-509.

29. Stamlerm J, Vaccaro O, Neaton JD, Wentworth D. Diabetes, other risk factors, and 12-yr cardiovascular mortality for men screened in the Multiple Risk Factor Intervention Trial. Diabetes Care. 1993;16:434-444.

30. Pahor M, Psaty BM, Furberg CD. New evidence on the prevention of cardiovascular events in hypertensive patients with type 2 diabetes. J Cardiovasc Pharmacol. 1998;32(Suppl 2):S18-S23.

31. Reaven G. Role of insulin resistance in human disease. Diabetes. 1988;37:1595-1607.

32. Grant PJ. Diabetes mellitus as a prothrombotic condition. J Inter Med. 2007;262:157-172.

33. Juhan-Vague I, Roul C, Alessi M, Ardissone J, Heim M, Vague P. Increased plasminogen activator inhibitor activity in non insulin dependent diabetic patients. Relationship with plasma insulin. Thromb Haemost. 1989;61:370-373.

34. Wagner D. Cell biology of von Willebrand factor. Annu Rev Cell Biol. 1990;6:217-246.

35. Corretti M, Anderson T, Benjamin E, et al. Guidelines for the ultrasound assessment of endothelial-dependent flow-mediated vasodilation of the brachial artery: a report of the International Brachial Artery Reactivity Task Force. J Am Coll Cardiol. 2002;39:257-265.

36. Perticone F, Caravolo R, Candigliota M. Obesity and body fat distribution induce endothelial dysfunction by oxidativestress. Protective effect of vitamin C. Diabetes. 2001;50:159-165.

37. Taylor A. Pathophysiology of hypertension and endothelial dysfunction in patients with diabetes mellitus. Endocrinol Metab Clin North Am. 2001;30:983-997.

38. Gryglewski R, Botting R, Vane J. Mediators produced by the endothelial cell. Hypertension. 1988;12:530-548.

39. Hajek A, Joist J, Baker R, Jarrett L. Demonstration and partial characterization of insulin receptors in human platelets. J Clin Invest. 1979;63:1060-1065.

40. Trovati M, Anfossi G. Influence of insulin and insulin resistance on platelet and vascular smooth muscle cell function. J Diabetes Complications. 2002;16:35-40.

41. Westerbacka J, Yki-Jarvinen H, Rissanen A, Vehkavaara S, Syrjälä M, R. L. Inhibition of platelet-collagen interaction. An in vivo action of insulin is abolished by insulin resistance in obesity. Arterioscler Thromb Vasc Biol. 2002;22:167-172.

42. Kroll M, Schafer A. Biochemical mechanisms of platelet activation. Blood. 1989;74:1181-1195.

43. Baldi S, Natali A, Buzzigoli G, Gavlan A, Sironi A, Ferrannini E. In vitro effect of insulin on intracellular calcium concentrations: relation to insulin resistance. Metabolism. 1996;45:1402-1407.
44. Khechai F, Ollivier V, Bridey F. Effect of advanced glycation end product-modified albumin on tissue factor expression by monocytes. Arterioscler Vasc Biol. 1997;17:2885-2890.

45. Lieuw-A-Fa M, van Hinsbergh V, Teerlink T. Increased levels of $\mathrm{N}$ (epsilon)-(carboxyethyl) lysine in type 1 diabetic patients with impaired renal function:correlation with markers of endothelial dysfunction. Nephrol Dial Transplant. 2004;19:631-636.

46. Watala C. May the alterations in lipid fluidity-mediated platelet hypersensitivity contribute to accelerated aging of platelets in diabetes mellitus? Med Hypotheses. 1991;36:142-145.

47. Antithrombotic Trialists Collaboration. Collaborative meta-analyses of randomized trials of antiplatelet therapy for prevention of death, myocardial infarction, and stroke in high risk patients. BMJ. 2002;324:71-86.

48. Smith JB, Willis AL. Aspirin selectively inhibits prostaglandin production in human platelets. Nat New Biol. 1971;231:235-237.

49. Patrignani P, Filabozzi P, Patrono CJ. Selective cumulative inhibition of platelet thromboxane production by low-dose aspirin in hearlthy subjects. Clin Invest. 1982;69:1366-1372.

50. Colwell J. American Diabetes Association. Aspirin therapy in diabetes (Position Statement). Diabetes Care. 2003;26:S87-S88.

51. Antiplatelet Trialists Collaboration. Collaborative overview of randomized trials of antiplatelets therapy. Prevention of death, myocardial infarction, and stroke by prolonged antiplatelet therapy in various categories of patients. BMJ. 1994;308:81-106.

52. Pearson TA, Blair SN, Daniels SR, et al. AHA Guidelines for Primary Prevention of Cardiovascular Disease and Stroke: 2002 Update. Consensus panel guide to comprehensive risk reduction for adult patients without coronary or other atherosclerotic vascular diseases. Circulation. 2002;106 388-391.

53. Collaborative Group of the Primary Prevention Project. Low-dose aspirin and vitamin $\mathrm{E}$ in people at cardiovascular risk: a randomized trial in general practice. Lancet. 2001;357:89-95.

54. Physicians' Health Study Research Group. Final report on the aspirin component of the ongoing Physicians'Health Study. $N$ Engl J Med. 1989;321:129-135.

55. ETDRS Investigators. Aspirin effects on mortality and morbidity in patients with diabetes mellitus: Early Treatment Diabetic Retinopathy Study Report. JAMA. 1992;268:1292-1300.

56. Hansson L, Zanchetti A, Carruthers SG. Effects of intensive bloodpressure lowering and low-dose aspirin in patients with hypertension: principal results of the hypertensive optimal treatment randomized trial. Lancet. 1998;351:1755-1762.

57. Pamukcu B. A review of aspirin resistance: definition, possible mechanisms, detection with platelet function tests, and its clinical outcomes. J Thromb Thrombolysis. 2007;23:213-222.

58. Barnes GD, Li J, Kline-Rogers E, et al. Dual antiplatelet agent failure: a new syndrome or clinical nonentity? Am Heart J. 2007;154 732-735.

59. Macchi L, Christiaens L, Brabant S, et al. Resistance to aspirin in vitro is associated with increased platelet sensitivity to adenosine diphosphate. Thromb Res. 2002;108:115-119.

60. Zimmermann N, Wenk A, Kim U, et al. Functional and biochemical evaluation of platelet aspirin resistance after coronary artery bypass surgery. Circulation. 2003;108:542-547.

61. Michelson AD. Platelet function testing in cardiovascular diseases. Circulation. 2004;110:e489-e493.

62. Tantry US, Blinden KP, Gurbel PA. Overstimation of platelet aspirin resistance detection by thrombelastograph platelet mapping and validation by conventional aggregometry using arachidonic acid stimulation. J Am Coll Cardiol. 2005;46:1705-1709.

63. Mason PJ, Jacobs AK, Freedman JE. Aspirin resistance and atherothrombotic disease. J Am Coll Cardiol. 2005;46:986-993.

64. Hurlen M, Seljeflot I, Arnesen H. Increased platelet aggregability during exercise in patients with previous myocardial infarction. Lack of inhibition by aspirin. Thromb Res. 2000;99:487-494.

65. Kawasaki T, Ozeki Y, Igawa T, Kambayashi J. Increased platelet sensitivity to collagen in individuals resistant to low dose aspirin. Stroke. 2000;31:591-595. 
66. Angiolillo DJ, Fernandez-Ortiz A, Bernardo E, et al. Influence of aspirin resistance on platelet function-profiles in patients on long-term aspirin and clopidogrel after percutaneous coronary intervention. Am J Cardiol. 2006;97:38-43.

67. Angiolillo DJ, Fernandez-Ortiz A, Bernardo E, et al. Platelet function profiles in patients with type 2 diabetes and coronary artery disease on combined aspirin and clopidogrel treatment. Diabetes. 2005;54:2430-2435.

68. Dichiara J, Blinden KP, Tantry US, et al. The effect of aspirin dosing on platelet function in diabetic and nondiabetic patients: an analysis from the aspirin-induced platelet effect (ASPECT) study. Diabetes 2007;56:3014-3019

69. Catella-Lawson F, Reilly M, Kapoor S, et al. Cyclooxygenase inhibitors and the platelet effects of aspirin. $N$ Engl J Med. 2001;345:1809-1817.

70. Cipollone F, Ciabattoni G, Patrignani P, et al. Oxidant stress and aspirin insensitivity thromboxane biosynthesis in severe unstable angina. Circulation. 2000;102:1007-1013.

71. Macchi L, Christiaens L, Brabant S, et al. Resistance in vitro to low-dose aspirin is associated with platelet PlA1 (GPIIIa) polymorphism but not with C807T (GPIa/IIa) and C-5T kozak (GPIb $\alpha$ ) polymorphisms. J Am Coll Cardiol. 2003;42:1115-1119.

72. Quinn M, Topol EJ. Common variations in platelet glycoproteins: pharmacogenomic implications. Pharmacogenomics. 2001;2:341-352.

73. Eikelboom JW, Hirsh J, Weitz JI, Johnston M, Yi Q, Yusuf S Aspirin-resistant thromboxane biosynthesis and the risk of myocardial infarction, stroke, or cardiovascular death in patients at high risk for cardiovascular events. Circulation. 2002;105:1650-1655.

74. Sacco M, Pellegrini F, Roncaglioni MC, Avanzini F, Tognoni G, Nicolucci A. Primary prevention of cardiovascular events with low-dose aspirin and vitamin $E$ in type 2 diabetic patients: results of the Primary Prevention Project (PPP) trial. Diabetes Care. 2003;26:3264-3272.

75. Quinn MJ, Fitzgerald DJ. Ticlopidine and clopidogrel. Circulation. 1999;100:1667-1672.

76. Bertrand ME, Rupprecht HJ, Urban P, Gershlick AH; CLASSICS Investigators. Double-blond study of the safety of clopidogrel with and without a loading dose in combination with aspirin compared with ticlopidine in combination with aspirin after coronary stenting: the clopidogrel aspirin stent international cooperative study (CLASSICS). Circulation. 2000;102:624-629.

77. Sabatine MS, Cannon CP, Gibson CM. Clopidogrel as Adjunctive Reperfusion Therapy (CLARITY)-Thrombolysis in Myocardial Infarction (TIMI) 28 Investigators. Addition of Clopidogrel to aspirin and fibrinolytis therapy for myocardial infarction with ST-segment elevation. CLARITYTIMI 28 Investigators. N Engl J Med. 2005;352:1179-1189.

78. Steinhubl SR, Berger PB, Mann JT, et al; CREDO Investigators. Clopidogrel for the Reduction of Events During Observation. Early and sustained dual oral antiplatelet therapy following percutaneous coronary intervention: a randomized controlled trial. JAMA. 2002;288:2411-2420.

79. Yusuf S, Zhao F, Metha SR. Clopidogrel in Unstable Angina to Prevent Recurrent Events Trial Investigators. Effects of clopidogrel in addition to aspirin in patients with acute coronary syndromes without ST-segment elevation. N Engl J Med. 2001;345:494-502.

80. Braunwald E, Antman EM, Beasley JM, American College of Cardiology, American Heart Association. Committee on the management of Patients with Unstable Angina. ACC/AHA 2002 guideline update for the management of patients with unstable angina and non-ST-segment elevation myocardial infarction-summary article: a report of the American College of Cardiology/American Heart Association task force on practice guidelines (Committee on the Management of Patients with Unstable Angina). $\mathrm{J} \mathrm{Am} \mathrm{Coll} \mathrm{Cardiol.}$ 2002;40:1366-1374.

81. Chen ZM, Jiang LX, Chen YP. COMMIT (ClOpidogrel and metoprolol in Myocardial Infarction Trial) collaborative group. Addition of clopidogrel to aspirin in 45,852 patients with acute myocardial infarction: randomised placebo-controlled trial. Lancet. 2005;366:1607-1621.

82. CAPRIE Steering Committee. A randomized blinded, trial of clopidogrel versus aspirin in patients at risk of ischaemic events (CAPRIE). Lancet. 1996;348:1329-1339.
83. Bhatt D, Marso S, Hirsch A. Amplified benefit of clopidogrel versus aspirin in patients with diabetes mellitus. Am J Cardiol. 2002;90:625-628.

84. CAPRIE Steering Committee. A randomized, blinded, trial of clopidogrel versus aspirin in patients at risk of ischaemic events. (CAPRIE). Lancet. 1996;348:1329-1339.

85. Hochholzer W, Trenk D, Frundi D, Neumann FJ. Whole blood aggregometry for evaluation of the antiplatelet effects of clopidogrel. Thromb Res. 2007;119:285-291.

86. Angiolillo DJ, Fernandez-Ortiz A, Bernardo E, Alfonso F, Macaya C, Bass TA, Costa MA. Variability in individual responsiveness to clopidogrel: clinical implications, management and future perspectives. $J$ Am Coll Cardiol. 2007:49:1505-1516.

87. Wiviott SD, Antman EM. Clopidogrel resistance: a new chapter in a fast-moving story. Circulation. 2004;109:3064-3067.

88. Gurbel PA, Blinden KP, Hiatt BL, O'Connor CM. Clopidogrel for coronary stenting. Response, variability, drug resistance and the effect of pre-treatment platelet reactivity. Circulation. 2003;107:2908-2913.

89. Jaremo P, Lindahl TL, Fransson SG, Richter A. Individual variations of platelet inhibition after loading doses of clopidogrel. J Intern Med. 2002;252:233-238.

90. Angiolillo DJ, Fernandez-Ortiz A, Bernardo E, et al. Identification of low responders to a $300 \mathrm{mg}$ clopidogrel loading dose in patients undergoing coronary stenting. Thromb Res. 2005;115:101-108.

91. Angiolillo DJ, Fernandez-Ortiz A, Bernardo E, et al. High clopidogrel loading dose during coronary stenting: effects on drug response and interindividual variabilty. Eur Heart J. 2004;25:1903-1910.

92. Gurbel PA, Blinden KP, Hayes KM, Yoho JA, Herzog WR, Tantry US The relation of dosing to clopidogrel responsiveness and the incidence of high post-treatment platelet aggregation in patients undergoing coronary stenting. J Am Coll Cardiol. 2005;45:1392-1396.

93. Gurbel PA, Blinden KP. Durability of platelet inhibition by clopidogrel. Am J Cardiol. 2003;91:1123-1125.

94. Gresele P, Gugliemini G, De Angelis M, et al. Acute, short-term hyperglycemia enhances shear stress-induced platelet activation in patients with type 2 diabetes mellitus. J Am Coll Cardiol. 2003;41:1013-1020.

95. Davì G, Averna M, Catalano I, Barbagallo CM, Giovenco E, Carroccio A, Notarbartolo A, Strano A. Platelet function in patients with type 2 diabetes mellitus: the effect of glycemic control. Diabetes Res Clin Pract. 1989;10:7-12.

96. Ferreira IA, Eybrechts KL, Mocking AI, Kroner C, Akkerman JW. IRS-1 mediates inhibition of $\mathrm{Ca}^{2+}$ mobilization by insulin via the inhibitory G-protein Gi. J Biol Chem. 2004;279:3254-3264.

97. Liu D, Maier A, Scholze A, et al. High glucose enhances transient receptor potential channel canonical type 6-dependent calcium influx in human platelets via phosphatidylinositol 3-kinase-dependent pathway. Arterioscler Thromb Vasc Biol. 2008;28:746-751.

98. Ferreira IA, Mocking AI, Feijge MA. Platelet inhibition by insulin is absent in type 2 diabetes mellitus. Arterioscler Thromb Vasc Biol. 2006;26:417-422.

99. Patrono C, Garcia Rodriguez LA, Landolfi R, Baigent C. Lowdose aspirin for the prevention of atherothrombosis. $N$ Engl J Med. 2005;353:2373-2383.

100. Sibbing D, von Beckerath O, Schomig A, kastrati A, von Beckerath N. Diabetes mellitus and platelet function after administration of aspirin and a single dose of clopidogrel. J Thromb Haemost. 2006;4:2566-2568.

101. Lotrionte M, Biondi-Zoccai GG, Agostoni P, et al. Meta-analysis appraising high clopidogrel loading in patientes undergoing percuntaneous coronary intervention. Am J Cardiol. 2007;100:1199-1206.

102. Lee SW, Park SW, Hong MK, et al. Triple versus dual antiplatelet therapy after coronary stenting: impact on stent thrombosis. J Am Coll Cardiol. 2005;46:1833-1837.

103. Biondi-Zoccai GG, Lotrionte M, Anselmino M, et al. Systematic review and meta-analysis of randomized clinical trials appraising the impact of cilostazol after percutaneous coronary intervention. $\mathrm{Am}$ Heart J. 2008;155:1081-1089. 
104. Lee SW, Park SW, Kim YH, et al. Drug-eluting stenting followed by cilostazol treatment reduces late restenosis in patients with diabetes mellitus the DECLARE-DIABETES trial (A Randomized Comparison of Triple Antiplatelet Therapy with Dual Antiplatelet Therapy After Drug-Eluting Stent Implantation in Diabetic Patients). $J$ Am Coll Cardiol. 2008;51:1181-1187.

105. Angiolillo DJ, Capranzano P, Goto S, et al. A randomized study assessing the impact of cilostazol on platelet function profiles in patients with diabetes mellitus and coronary artery disease on dual antiplatelet therapy: results of the OPTIMUS-2 study. Eur Heart $J$. 2008;29:2202-2211.

106. Angiolillo DJ, Costa MA, Shoemaker SB, et al. Functional effects of high clopidogrel maintenance dosing in patients with inadequate platelet inhibition on standard dose treatment. Am J Cardiol. 2008;101:440-445.

107. Vorchheimer DA, Badimon JJ, Fuster V. Platelet glycoprotein IIb/IIIa receptors antagonists in cardiovascular disease. JAMA. 1999;281:1407-1414.

108. Wiviott SD, Trenk D, Frelinger AL, et al; PRINCIPLE-TIMI 44 Investigators. Prasugrel compared with high loading- and maintenance-dose clopidogrel in patients with planned percutaneous coronary intervention: the Prasugrel in Comparison to Clopidogrel for Inhibition of Platelet Activation and Aggregation-Thrombolysis in Myocardial Infarction 44 trial. Circulation. 2007;116:2923-2932.

109. Wallentin L, Varenhorst C, James S, et al. Prasugrel achieves greater and faster $\mathrm{P} 2 \mathrm{Y}_{12}$ receptor-mediated platelet inhibition than clopidogrel due to more efficient generation of its active metabolite in aspirin-treated patients with coronary artery disease. Eur Heart $J$. 2008;29:21-30.

110. Wiviott SD, Brunwald E, McCabe CH, et al; TRITON-TIMI 38 Investigators. Prasugrel versus clopidogrel in patients with acute coronary syndromes. New Engl J Med. 2007;357:2001-2015.

111. Lemp GF, Vander Zwaag R, Hughes JP. Association between the severity of diabetes mellitus and coronary arterial atherosclerosis. $\mathrm{Am}$ J Cardiol. 1987;60:1015-1019.

112. Goraya TY, Leibson CL, Palumbo PJ. Coronary atherosclerosis in diabetes mellitus: a population-based autopsy study. $\mathrm{J} \mathrm{Am} \mathrm{Coll}$ Cardiol. 2002;40:946-953.

113. Flaherty JD, Davidson CJ. Diabetes and coronary revascularization. JAMA. 2005;293:1501-1508.

114. Karha J, Bhatt DL. Percutaneous coronary intervention in diabetics. Rev Endocr Metab Disord. 2004;5:277-285.

115. Dharam J, Kumbhani SM, Bavry AA, Kamdar A, Helton TJ, Bhatt DL. The effect of drug-eluting stents on intermediate angiographic and clinical outcomes in diabetic patients: Insights from randomized clinical trialsshowed. Am Heart J. 2008;155:640-647.

116. Sabaté M, Jimenez-Quevedo P, Angiolillo DJ, et al. Randomized comparison of sirolimus-eluting stent versus standard stent for percutaneous coronary revascularization in diabetic patients: the diabetes and sirolimus-eluting stent (DIABETES) trial. Circulation. 2005;112:2175-2183.

117. Dibra A, Kastrati A, Mehilli J; ISAR-DIABETES Study Investigators. Paclitaxel-eluting or sirolimus-eluting stents to prevent restenosis in diabetic patients. N Engl J Med. 2005;353:663-670.

118. Tomai F, Reimers B, De Luca L, et al. Head-to-head comparison of sirolimus- and paclitaxel-eluting stent in the same diabetic patient with multiple coronary artery lesions: a prospective, randomized, multicenter study. Diabetes Care. 2008;31:15-19.

119. Baumgart D, Klauss V, Baer F, et al; SCORPIUS Study Investigators. One-year results of the SCORPIUS study: a German multicenter investigation on the effectiveness of sirolimus-eluting stents in diabetic patients. J Am Coll Cardiol. 2007;50:1627-1634.

120. Maresta A, Varani E, Balducelli M, et al; DESSERT Investigators. Comparison of effectiveness and safety of sirolimus-eluting stents versus bare-metal stents in patients with diabetes mellitus (from the Italian Multicenter Randomized DESSERT Study). Am J Cardiol. 2008;101:1560-1566.
121. Daemen J, Wenaweser P, Tsuchida K, et al. Early and late coronary stent thrombosis of sirolimus-eluting and paclitaxel-eluting stents in routine clinical practice: data from a large two-institutional cohort study. Lancet. 2007;369:667-678.

122. Stone GW, Moses JW, Ellis SG. Safety and efficacy of sirolimus and paclitaxel- eluting coronary stents. $N$ Engl J Med. 2007;356:998-1008.

123. Kastrati A, Mehilli J, Pache J. Analysis of 14 trials comparing sirolimus-eluting stents with bare-metal stents. $N$ Engl J Med. 2007;356:1030-1039.

124. Mauri L, Hsieh W-H, Massaro JM, Ho KKL, D’Agostino R, Cutlip DE. Stent thrombosis in randomized clinical trials of drug-eluting stents. N Engl J Med. 2007;356:1020-1029.

125. Stettler C, Wandel S, Allemann S, et al. Outcomes associated with drug-eluting and bare-metal stents: a collaborative network metaanalysis. Lancet. 2007;370:937-948.

126. Hodgson JM, Stone GW, Lincoff AM, et al; Society for Cardiovascular Angiography and Interventions. Late stent thrombosis: considerations and practical advice for the use of drug-eluting stents: a report from the Society for Cardiovascular Angiography and Interventions Drug-eluting Stent Task Force. Catheter Cardiovasc Interv. 2007;69(3):327-333.

127. Kapur A, Malik IS, Bagger JP, et al. The Coronary Artery Revascularisation in Diabetes (CARDia) trial: background, aims, and design. Am Heart J. 2005;149:13-19.

128. FREEDOM I. Future revascularization evaluation in patients with Diabetes Mellitus: optimal management of multivessel disease. FREEDOM Trial, 2006

129. Ong AT, Hoye A, Aoki J, et al. Thirty-day incidence and six-month clinical outcome of thrombotic stent occlusion after bare-metal, sirolimus, or paclitaxel stent implantation. J Am Coll Cardiol. 2005;45:947-953.

130. Cutlip DE, Windecker S, Mehran R, et al. Clinical end points in coronary stent trials: a case for standardized definitions. Circulation. 2007;115:2344-2351.

131. Luscher TF, Steffel J, Eberli FR, et al. Drug-eluting stent and coronary thrombosis: biological mechanisms and clinical implications. Circulation. 2007;115:1051-1058.

132. Virmani R, Guagliumi G, Farb A, et al. Localized hypersensitivity and late coronary thrombosis secondary to a sirolimus-eluting stent: should we be cautious? Circulation. 2004;109:701-705.

133. West NE, Ruygrok PN, Disco CM, et al. Clinical and angiographic predictors of restenosis after stent deployment in diabetic patients. Circulation. 2004;109:867-873.

134. Niles NW, McGrath PD, Malenka D, Group. NNECDS. Survival of patients with diabetes and multivessel coronary artery disease after surgical or percutaneous coronary revascularization: results of a large regional prospective study. J Am Coll Cardiol. 2001;37:1008-1015.

135. Lincoff AM. Important triad incardiovascular medicine: diabetes, coronary intervention and platelet glycoprotein IIb/IIIa receptor blokade. Circulation. 2003;107:1556-1559.

136. Gurbel PA, Blinden KP, Samara W, Yoho JA, Hayes K, Fissha MZ, Tantry US. Clopidogrel effect on platelet reactivity in patients with stent thrombosis: results of the CREST study. J Am Coll Cardiol. 2005;46:1827-1832.

137. Buonamici P, Marcucci R, Migliorini A, et al. Impact of platelet reactivity after clopidogrel administration on drug-eluting stent thrombosis. $J$ Am Coll Cardiol. 2007;49:2312-2317.

138. de la Torre-Hernández JM, Alfonso F, Hernández F, et al. Drugeluting stent thrombosis: results from the multicenter Spanish registry ESTROFA (Estudio ESpañol sobre TROmbosis de stents FArmacoactivos). J Am Coll Cardiol. 2008;51:986-990.

139. Kumbhan DJ, Bavry AA, Kamdar AR, Helton TJ, Bhatt DL. The effect of drug-eluting stents on intermediate angiographic and clinical outcomes in diabetic patients: Insights from randomized clinical trials. Am Heart J. 2008; 155:640-647.

140. Spaulding C, Daemen J, Boersma E, Cutlip DE, Serruys PW. A pooled analysis of data comparing sirolimus-eluting stents with baremetal stents. N Engl J Med. 2007;356:989-997. 
141. Urban P, Gershlick AH, Guagliumi G, et al. Safety of coronary sirolimus-eluting stents in daily clinical practice: one-year follow-up of the e-Cypher registry. Circulation. 2006;113:1434-1441.

142. Machecourt J, Danchin N, Lablanche J. Risk factors for stent thrombosis after implantation of sirolimus-eluting stents in diabetic and non-diabetic patients. The EVASTENT matched-cohort registry. $J \mathrm{Am}$ Coll Cardiol. 2007;50:501-508.
143. Kirtane AJ, Ellis SG, Dawkins KD, et al. Paclitaxel-eluting coronary stents in patients with diabetes mellitus pooled analysis from 5 randomized trials. $J$ Am Coll Cardiol. 2008;51:708-715.

144. Kuchulakanti PK, Chu WW, Torguson R, et al. Correlates and long-term outcomes of angiographically proven stent thrombosis with sirolimus- and paclitaxel-eluting stents. Circulation. 2006;113:1108-1113. 
